\title{
11
}

\section{A Framework for Understanding Whole-Earth Carbon Cycling}

\author{
CIN-TY A. LEE, HEHE JIANG, RAJDEEP DASGUPTA, AND MARK TORRES
}

\subsection{Introduction}

Climate, specifically Earth's surface temperature, is controlled by solar insolation, albedo, and the greenhouse gas content in the atmosphere. ${ }^{1,2}$ Solar insolation relates to the solar radiative flux, which depends on changes in the sun's luminosity and the planet's distance from the sun. Albedo represents the fraction of the solar radiative flux reflected back into space, which is influenced by clouds, ice sheets, vegetation, the land/ocean ratio, and aerosols. That part of the solar flux not reflected back into space is absorbed by Earth's surface and re-radiated in the form of infrared energy. In the presence of certain gases that absorb infrared radiation, this re-radiated energy heats the atmosphere.

Radiative balance calculations show that, without greenhouse gases, Earth's average surface temperature would be well below the freezing point of water. ${ }^{1}$ Geologic evidence for an active hydrologic cycle as far back as the early Archean suggests that Earth's surface temperature has not strayed wildly from the triple point of water, requiring the warming effects of greenhouse gases. Even in the first 2 billion years, when the sun's luminosity was substantially lower than today's, surface temperatures were still conducive to liquid water. What is remarkable, then, is that the amount of greenhouse gases in the atmosphere must vary in a way that buffers Earth's surface temperature, even when other factors like solar luminosity change. If greenhouse gases fall below some threshold, liquid water would freeze over globally, or if a threshold is exceeded, temperatures could rise to a level at which most of the water would be in the form of vapor, not unlike Venus today. This billion-year "stability" of Earth's climate indicates that greenhouse gas contents are regulated by an internal thermostat to maintain a clement climate. ${ }^{2}$

Superimposed on this billion-year climatic stability are shorter-term climatic fluctuations ranging from long-lived (10+ My) greenhouse and icehouse intervals ${ }^{3,4}$ to $<100-k y$ oscillations associated with Milankovitch orbital dynamics. ${ }^{5}$ Icehouse conditions of the last 30 My have been characterized by large, permanent polar ice sheets (Figure 11.1a) that wax and wane with orbital cycles. ${ }^{6}$ In contrast, the late Mesozoic to early Cenozoic greenhouse interval (150-50 Ma) was characterized by average surface temperatures $>10^{\circ} \mathrm{C}$ higher than today and free of permanent ice sheets (Figure 11.1a). ${ }^{4}$ Between 600 and $800 \mathrm{Ma}$, Earth may have temporarily experienced runaway icehouses, known as 

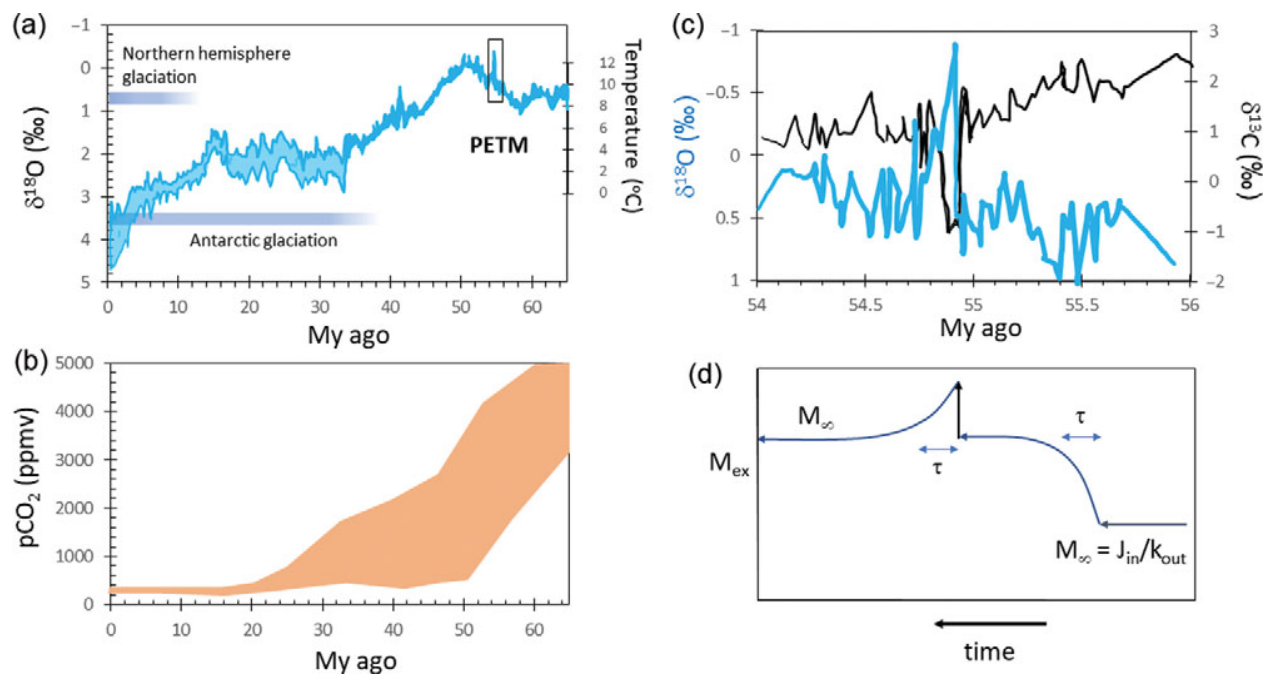

Figure 11.1 (a) Oxygen isotope record of seawater since $65 \mathrm{Ma}$ with corresponding estimates of temperature on the right-hand axis (from Zachos et al. ${ }^{4}$ ). Onsets of Antarctic and northern hemisphere glaciations are shown. Box denotes the Paleocene-Eocene thermal maximum (PETM), which is expanded in (b). (b) Paleo- $\mathrm{pCO}_{2}$ estimates for the last 65 My (adapted from Zachos et al. ${ }^{4}$ ). (c) Carbon and oxygen isotopic composition of seawater across the PETM (adapted from Zachos et al. $\left.{ }^{4}\right)$. (d) Schematic diagram of the mass of $\mathrm{C}$ in the exogenic system $\left(M_{e x}\right)$ versus time. This diagram shows the concepts of response time $(\tau)$ and steady state.

"Snowball" events, where temperatures got cold enough for continental ice sheets to develop at low latitudes.

Paleo-proxy data indicate that the partial pressure of atmospheric $\mathrm{CO}_{2}$, the dominant greenhouse gas for most of Earth's history, is generally high during greenhouse times and low during icehouses (Figure 11.1b).$^{9,10}$ Thus, understanding long-term climate variability requires an understanding of what controls the $\mathrm{C}$ content of the exogenic system, which we define here as the sum of the ocean, atmosphere, biosphere, and the thin veneer of reactive soil or marine sediments that support life (Figures 11.2 and 11.3). These exogenic reservoirs cycle rapidly between each other on timescales of days to thousands of years, allowing for short-term variability of atmospheric $\mathrm{CO}_{2}$. The exogenic $\mathrm{C}$ cycle operates on top of a much longer deep Earth $\mathrm{C}$ cycle, wherein the total amount of $\mathrm{C}$ in the exogenic system is controlled by fluxes into and out of Earth's interior, which we term the endogenic system (Figures 11.2 and 11.3).

The endogenic system includes $\mathrm{C}$ in the core, convecting mantle, and lithospheres (crust and lithospheric mantle). Endogenic $\mathrm{C}$ enters the exogenic system via volcanic degassing as well as metamorphic degassing and weathering of fossil organic $\mathrm{C}$ and carbonate. Carbon from the ocean, atmosphere, and biosphere is removed by carbonate precipitation and organic $\mathrm{C}$ burial, the former through an intermediate step of silicate weathering and the latter through photosynthesis. Subduction or deep burial of these carbonates and organic 


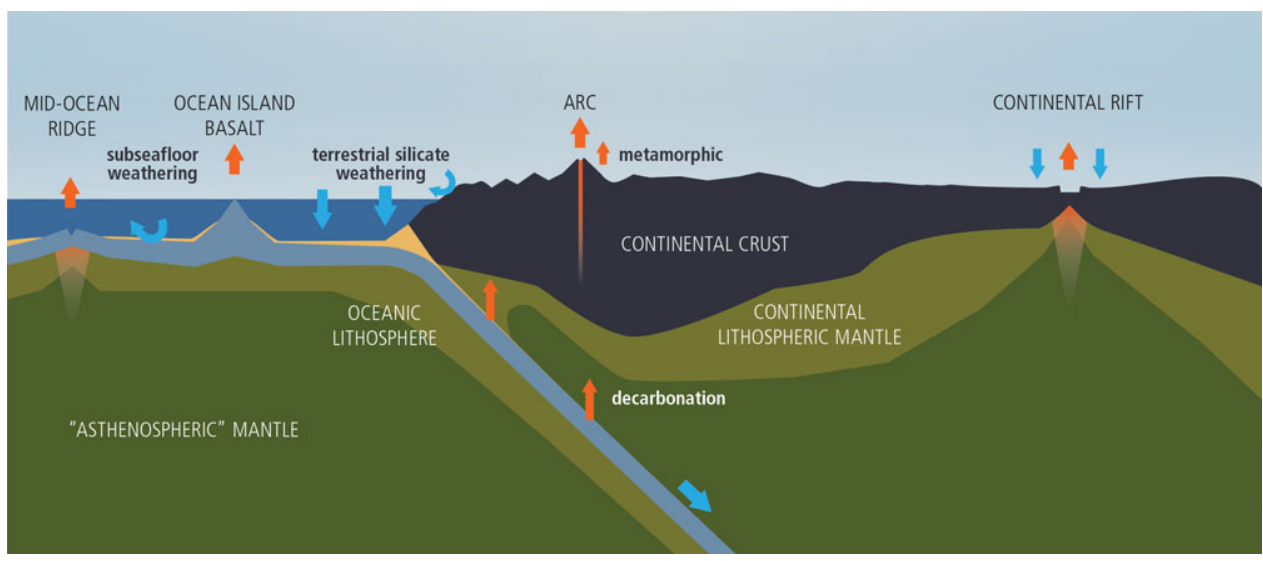

Figure 11.2 Cartoon (not to scale) showing how the whole-Earth $\mathrm{C}$ cycle relates to plate tectonics and the dynamics of the mantle. Orange arrows correspond to outgassing from Earth's interior. Blue arrows correspond to carbonate precipitation or organic $\mathrm{C}$ burial. Curved blue arrows represent terrestrial silicate weathering and seafloor weathering.

$\mathrm{C}$ is the mechanism by which exogenic $\mathrm{C}$ is transferred back into the endogenic system. The response time of the exogenic system to perturbations in $\mathrm{C}$ inputs or outputs is thought to be $\sim 10-100 \mathrm{ky}$, which would imply that on My timescales, inputs and outputs are roughly balanced, so that the total exogenic $\mathrm{C}$ budget is near steady state. ${ }^{27,28}$ The fact that Earth has fluctuated between long intervals of greenhouse or icehouse conditions implies that Earth transitions between different steady states, requiring that inputs from the endogenic system or the efficiency of weathering and organic $\mathrm{C}$ burial are not constant over My timescales. This chapter describes how $\mathrm{C}$ cycles between the endogenic and exogenic systems.

\subsection{Basic Concepts of Elemental Cycling}

\subsubsection{Steady State and Residence Time}

The rate of change of $\mathrm{C}$ mass in reservoir $i, d M_{i} / d t$, is given by

$$
\frac{d M_{i}}{d t}=\sum J_{j i}-\sum J_{i j}
$$

where the first term on the right represents the sum of all mass flows of $\mathrm{C}$ from reservoirs $j$ into $i$ and the second term right represents the sum of all mass flows of $\mathrm{C}$ out of reservoir $i$ to reservoirs $j$. More simply, (11.1) expressed as total inputs $J_{\text {in }}$ and outputs $J_{\text {out }}$ from a reservoir $M$, such as the entire exogenic system $M_{e x}$ (ocean + atmosphere + biosphere), is given by

$$
\frac{d M_{e x}}{d t}=J_{\text {in }}-J_{\text {out }}
$$




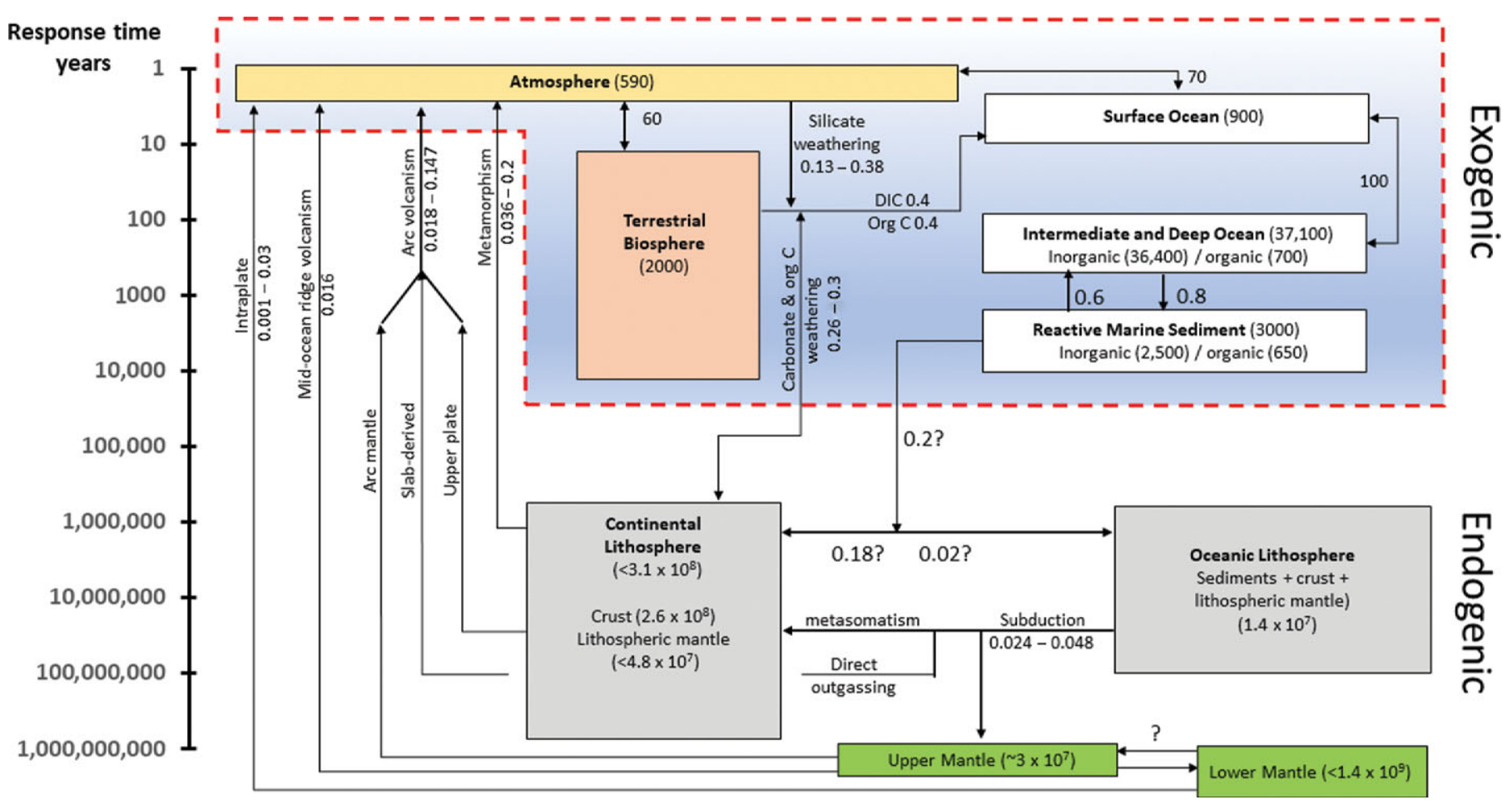

Figure 11.3 Box model describing the whole-Earth $\mathrm{C}$ cycle (excluding the core). Boxes within the red outlined region represent reservoirs within the exogenic system: the atmosphere, oceans, and the biosphere. All other boxes represent Earth's interior reservoirs and refer to the endogenic system. 
To completely model the $\mathrm{CO}_{2}$ content of the atmosphere (and not just the total exogenic system), both alkalinity and total $\mathrm{C}$ fluxes must be tracked, as the stoichiometry of these fluxes can vary considerably and their relative balance determines the proportion of exogenic $\mathrm{C}$ partitioned into the atmosphere. The treatment here, by ignoring this complexity, captures the first-order behavior of the system. $J_{\text {in }}$ would then represent all inputs of $\mathrm{C}$ (volcanic and metamorphic degassing) and $J_{\text {out }}$ the total $\mathrm{C}$ drawdown by silicate weathering (followed by carbonate burial) and organic $\mathrm{C}$ burial. $J_{\text {out }}$ must scale with the amount of $\mathrm{C}$ in the system; after all, if there is no $\mathrm{C}$ in the exogenic system, then the output must be zero. At the most basic level, we can adopt a linear scaling, such that

$$
J_{\text {out }}=k_{\text {out }} M_{\text {ex }}
$$

where $k_{\text {out }}$ is the sum of all rate constants $\left(\mathrm{s}^{-1}\right)$ describing the efficiency of different pathways by which $\mathrm{C}$ is sequestered from the exogenic system

$$
\left(k_{\text {out }}=\sum_{j} k_{i j}\right) \text {. }
$$

Analogous to radioactive decay, $k_{\text {out }}$ represents the probability that an atom of $\mathrm{C}$ is removed from the system per unit time. Because the output rate depends on the amount of $\mathrm{C}$ in the system, $k_{\text {out }}$ represents a negative feedback, which essentially counteracts any change in $\mathrm{C}$ in the system (see Lasaga ${ }^{29}$ ). As we will discuss later, $k_{\text {out }}$ represents a complex function of many processes. For example, $\mathrm{C}$ removal by silicate weathering and carbonate precipitation might be enhanced with greater water precipitation and temperature, both of which increase when atmospheric $\mathrm{CO}_{2}$ increases. ${ }^{2}$ The net effect is a negative feedback (Figure 11.4).

$J_{i n}$ must also scale with the mass of $\mathrm{C}$ from which the flux derives. If most of $J_{\text {in }}$ derives from volcanic degassing, then $J_{i n}=k_{i n} M_{m}$, where $M_{m}$ represents the mass of $\mathrm{C}$ in the mantle. If we assume that the mass of $\mathrm{C}$ in the mantle is much larger compared to that in the exogenic system, then $J_{\text {in }}$ is approximately constant and (11.2) becomes a first-order differential equation:

$$
\frac{d M_{e x}}{d t}=J_{\text {in }}-k_{\text {out }} M_{e x}
$$

Figure 11.3 (cont.) Arrows represent fluxes of $\mathrm{C}$ from one reservoir to another. Numbers by arrows represent fluxes in units of Gton C/y. Numbers in parentheses within each box refer to total reservoir mass of $\mathrm{C}$ (Gton $\mathrm{C})$. Reservoirs are placed according to the estimated residence or response time of $\mathrm{C}$ in the reservoir (see vertical axis). The vertical extent of each box represents the range of plausible residence/response times. The horizontal size of each box is arbitrary. Image inspired by Sundquist and Visser. ${ }^{11} \mathrm{C}$ fluxes internal to the exogenic system are taken from Sundquist and Visser. ${ }^{11-16}$ Silicate weathering flux is taken from Gaillardet et al. ${ }^{17}$ Mantle degassing fluxes are from Dasgupta and Hirschmann, ${ }^{18}$ Tucker et al., ${ }^{19}$ and other references discussed in the text. Metamorphic degassing data are from Kerrick and Caldeira. ${ }^{20}$ Volcanic arc emissions are from Burton et al. ${ }^{21}$ Cretaceous continental arcs are from Lee et al. ${ }^{22}$ and Lee and Lackey. ${ }^{23}$ Mt. Etna data are from Allard et al. ${ }^{24}$ Organic $\mathrm{C}$ weathering data are from Petsch, ${ }^{25}$ from which carbonate weathering rates are calculated. Anthropogenic emissions are from Friedlingstein et al. ${ }^{26}$ 


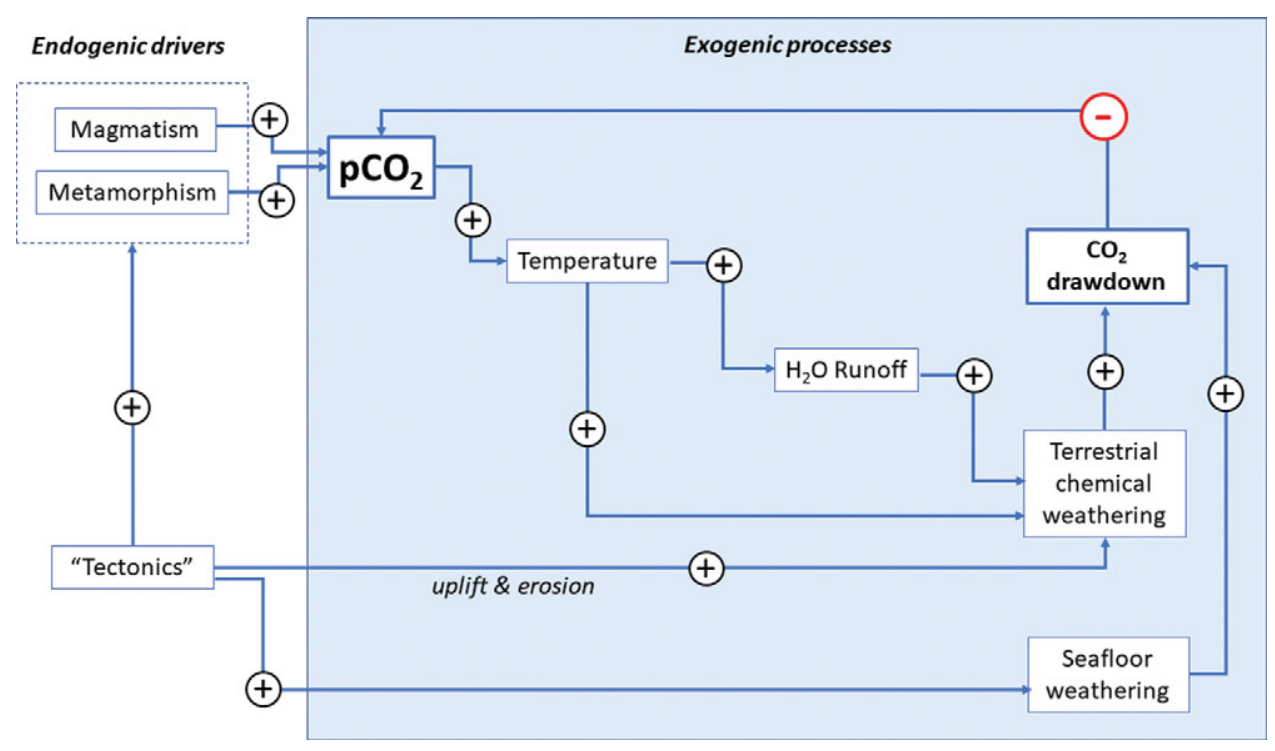

Figure 11.4 Feedback loop describing the silicate weathering feedback acting on the exogenic $\mathrm{C}$ system. Arrows correspond to transfer functions, with positive symbols indicating positive feedback and negative symbols representing negative feedback. Increases in $\mathrm{pCO}_{2}$ increase temperature, which leads to enhanced precipitation and runoff, accelerating chemical weathering rates and drawdown of $\mathrm{CO}_{2}$. Similarly, an increase in $\mathrm{pCO}_{2}$ increases seafloor weathering rates, increasing drawdown of $\mathrm{CO}_{2}$. Tectonics and mantle dynamics drive the entire system by: (1) increasing erosion rates during mountain building, thereby increasing the availability of weatherable substrate and drawdown rates of $\mathrm{CO}_{2}$; and/or (2) increasing magmatic or metamorphic inputs of $\mathrm{CO}_{2}$ into the exogenic system. Whether tectonics enhance degassing or drawdown will depend on the nature of the tectonic activity.

with the following solution:

$$
M_{\text {ex }}(t)=\frac{J_{\text {in }}}{k_{\text {out }}}+\left(M_{\text {ex }}^{o}-\frac{J_{\text {in }}}{k_{\text {out }}}\right) \exp \left(-k_{\text {out }} t\right) .
$$

Here, $M_{e x}^{o}$ represents an initial perturbation to the amount of $\mathrm{C}$ in the exogenic system. Equation (11.6) shows that the system will return exponentially to a steady state, given by

$$
M_{e x}^{\infty}=J_{\text {in }} / k_{\text {out }} .
$$

At steady state, inputs and outputs are balanced, hence the $\mathrm{C}$ content of the exogenic system does not evolve (steady state does not mean thermodynamic equilibrium). The time for the system to relax back to steady state after a perturbation (response time) is roughly the e-fold timescale of the system; that is:

$$
\tau_{\text {ex }}=1 / k_{\text {out }} \text {. }
$$

For a linear feedback, the response time is equivalent to the residence time of $\mathrm{C}$ in the system (Figure 11.1d). The residence time represents the average time a $\mathrm{C}$ atom remains in 
the exogenic system when the system is at steady state, $d M_{e x} / d t=0$. At steady state, $J_{\text {in }}=J_{\text {out }}$, such that the residence time of $\mathrm{C}$ in the system is given by

$$
\tau_{\text {ex }}^{r}=\frac{M_{e x}}{J_{\text {in }}}=\frac{M_{\text {ex }}}{J_{\text {out }}}=\frac{M_{e x}}{k_{\text {out }} M_{\text {ex }}}=\frac{1}{k_{\text {out }}} .
$$

When negative feedbacks operate, a system perturbed suddenly, such as by a pulse of $\mathrm{CO}_{2}$ outgassing, will eventually return to a steady state, defined by the ratio of the external forcings (e.g. the input) to the efficiency of the negative feedback, $k_{\text {out }}$ (11.6). On timescales longer than the response time of the system, the $\mathrm{C}$ in the system should evolve toward a steady state, after which the only processes that can change the $\mathrm{C}$ content in the exogenic system would be temporal changes in the forcings, such as changes in magmatic or metamorphic activity, or changes in the efficiency of carbonate precipitation, which may relate to changes in tectonics and the efficiency of silicate weathering.

The response time for $\mathrm{C}$ in the exogenic system has been determined in two ways. One approach is to take the mass of $\mathrm{C}$ in the exogenic system and divide it by the measured inputs or outputs to obtain residence times. This approach is only valid if the measured inputs or outputs truly represent steady-state conditions. Another approach is to measure the relaxation time of a perturbed system, with one example being the $\mathrm{C}$ isotope excursion observed at the Paleocene-Eocene thermal maximum (PETM). ${ }^{4}$ Both approaches suggest that $C$ in the exogenic system has a response time between 10 and 100 ky (Figure 11.1c and d). ${ }^{4}$ Thus, on My timescales, the $\mathrm{C}$ content of the exogenic system should be close to steady state. However, the fact that atmospheric $\mathrm{CO}_{2}$ nevertheless changes on My and Gy timescales means that tectonic/magmatic forcings or the global efficiency of the negative feedbacks must change with time as Earth evolves. In other words, Earth's exogenic system is characterized by time-varying steady states or a baseline $\mathrm{C}$ content and climate. On short timescales, the exogenic system is not strongly influenced by the deep Earth, but on My timescales, the total budget of the exogenic $\mathrm{C}$ is controlled by the deep Earth through degassing and weathering.

\subsubsection{Climatic Drivers versus Negative Feedbacks}

The most important feature of negative-feedback systems is that steady state, if given enough time, will eventually be attained. Without a negative feedback, where the output does not depend on the amount of $\mathrm{C}$ in the exogenic system, a system is unlikely to attain steady state. In such a system, the $\mathrm{C}$ content of the exogenic system would rise indefinitely if inputs exceeded outputs or eventually decline to zero if outputs exceeded inputs. Earth's climate has changed through time, but liquid water appears to have been present for almost all of Earth's history, implying that inputs and outputs must be balanced on long timescales, which in turn implies that $\mathrm{C}$ in the exogenic system and climate is controlled by a negative-feedback mechanism. Any imbalances in inputs and outputs must be transient and occur on timescales shorter than the response time of exogenic $\mathrm{C}$ to perturbations (Figure 11.1d). ${ }^{27}$ 
(a)

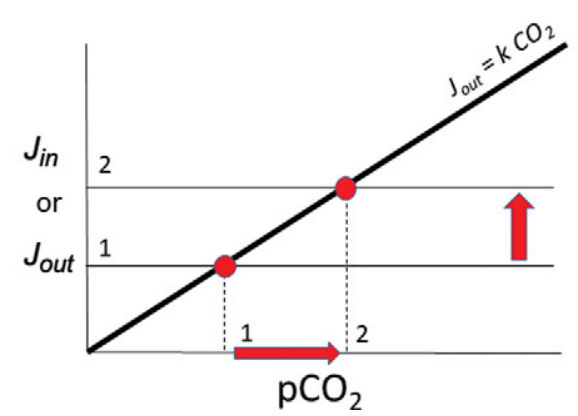

(b)

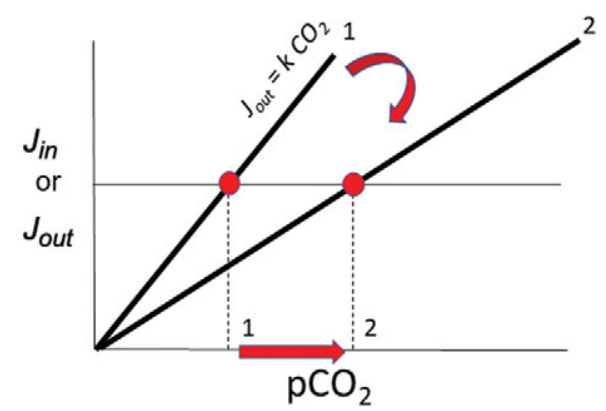

Figure 11.5 Inputs $J_{\text {in }}$ and outputs $J_{\text {out }}$ as a function of $\mathrm{pCO}_{2}$. Geologic inputs are assumed not to depend on exogenic $\mathrm{C}$ and are thus represented as horizontal lines. Output rate depends on $\mathrm{pCO}_{2}$, with the slope $k$ representing the sensitivity of the negative weathering feedback. The intersection between $J_{\text {in }}$ and $J_{\text {out }}$ represents steady state, where $J_{\text {in }}=J_{\text {out }}$. The $\mathrm{pCO}_{2}$ at this intersection represents steady-state $\mathrm{pCO}_{2}$. In (a), we show that steady-state $\mathrm{pCO}_{2}$ increases by increasing $J_{\text {in }}$ while holding the weathering feedback constant (red arrows from states 1 to 2 show an increase in steady-state $\mathrm{pCO}_{2}$ ). In (b), we hold inputs constant but decrease the sensitivity of the weathering feedback. This causes steady-state $\mathrm{pCO}_{2}$ to increase without any change in the input.

Baseline or steady-state $\mathrm{C}$ in the exogenic system is driven by the inputs and modulated by the efficiency of the outputs. The greater the kinetic rate constant for $\mathrm{C}$ removal from the exogenic system, the more sensitive the negative feedback. In a steady-state system, this concept is illustrated well in a graph of $\mathrm{C}$ input or output versus total $\mathrm{C}$ in the exogenic system. ${ }^{30,31}$ For a linear system, the sensitivity of the negative feedback is the slope of the output as shown in Figure 11.5. Because the input of $\mathrm{C}$ from the deep Earth does not depend on the amount of exogenic $\mathrm{C}$, the output function is represented by a horizontal line in Figure 11.5a. The intersection between the two lines defines the steady state. For a given sensitivity, $k$, the only way to change steady-state exogenic $\mathrm{C}$ is to change inputs. If inputs are instead held constant, exogenic $\mathrm{C}$ can only change by changing the strength (slope) of the weathering feedback. If exogenic C were to suddenly decrease below the system's steady state, inputs would temporarily exceed outputs, returning exogenic $\mathrm{C}$ contents back to steady-state values. Conversely, if exogenic $\mathrm{C}$ contents were to suddenly increase, outputs would then exceed inputs, eventually returning the system to steady state. These concepts are shown in Figure 11.5b by keeping track of the intersection of the input and output functions. If the system were to become more efficient at $\mathrm{C}$ drawdown (higher $k$ ), such as if Earth was characterized by a global increase in mountain building and erosion, steady-state exogenic $\mathrm{C}$ would decrease. If drawdown efficiency were to decrease, such as through decreased weatherability of continents, steady-state exogenic $\mathrm{C}$ would increase without any change in the input (Figure 11.5b). Most importantly, if the negative-feedback efficiency is strong, then large changes in the inputs are required to change exogenic $\mathrm{C}$, 
which is to say that the exogenic C content is buffered. This is why Earth's climate, while variable over time, has rarely veered to extreme climatic conditions.

It is often debated whether Earth's climate and exogenic $\mathrm{C}$ is input or sink driven. This debate is not about whether inputs or outputs are in balance because, on long timescales, they are in balance. ${ }^{32}$ The crux of this debate is whether changes in the $\mathrm{C}$ content of the exogenic system are controlled by changes in input or changes in the efficiency of the negative feedback (Figure 11.5). The former involve changes in magmatic, metamorphic, or weathering-related outgassing rates, while the latter involve changing the efficiency of weathering and organic $\mathrm{C}$ burial.

\subsubsection{When Systems Transition to New Steady States}

Despite the overall stability of Earth's climate, there are examples when Earth or other planets have veered toward extreme climatic states. The Snowball climate of the Neoproterozoic, when Earth is thought to have frozen over, is an example of runaway cooling. ${ }^{8}$ Mars represents an example of a permanent icehouse, with surface temperatures of $-55^{\circ} \mathrm{C}$ and no active hydrologic cycle. ${ }^{33,34}$ Permanent greenhouse characterizes Venus, where surface temperatures are $460^{\circ} \mathrm{C}$ and the atmosphere is made of $96 \% \mathrm{CO}_{2} \cdot{ }^{33,34}$ Earth itself may have undergone short-lived excursions to hothouse conditions. These include the PETM and the various hyperthermals around that time. .,35,36 $^{-10}$

In a linear system, runaway processes cannot happen. However, negative-feedback mechanisms need not scale linearly with exogenic $\mathrm{C}$ content. For example, if the ratelimiting step for silicate weathering and precipitation of carbonates becomes the rate at which fresh new rock is exposed to the atmosphere, one could envision a "threshold" of atmospheric $\mathrm{CO}_{2}$ content above which further increases in $\mathrm{CO}_{2}$ do not result in increased weathering. Similarly, a scenario could be envisioned in which surface temperatures drop to a threshold below which weathering kinetics become negligible, and because surface temperature is in part controlled by the amount of greenhouse gases, this translates to a threshold of atmospheric $\mathrm{CO}_{2}$ below which weathering rates are insensitive to $\mathrm{CO}_{2}$. Thus, the functional form for the negative feedback might involve low-sensitivity regimes at low and high atmospheric $\mathrm{CO}_{2}$ separated by a sensitive, quasi-linear regime at intermediate $\mathrm{CO}_{2}$ contents (Figure 11.6). For a scenario in which $\mathrm{C}$ inputs to the exogenic system do not depend on atmospheric $\mathrm{CO}_{2}$, one can track how steady-state exogenic $\mathrm{C}$ varies as inputs vary. From Figure 11.6, we see that when inputs rise toward an upper threshold, steady-state exogenic $\mathrm{C}$ contents can rise uncontrollably, leading to a runaway greenhouse. If inputs decrease below some lower threshold, steady-state exogenic C contents will plummet, resulting in runaway icehouse conditions. Crossing these thresholds may move the planet to a different steady state, where a new type of negative feedback operates (Figure 11.7). Understanding the functional form of global weathering feedbacks is thus critical to understanding where these thresholds lie in terms of exogenic C. 

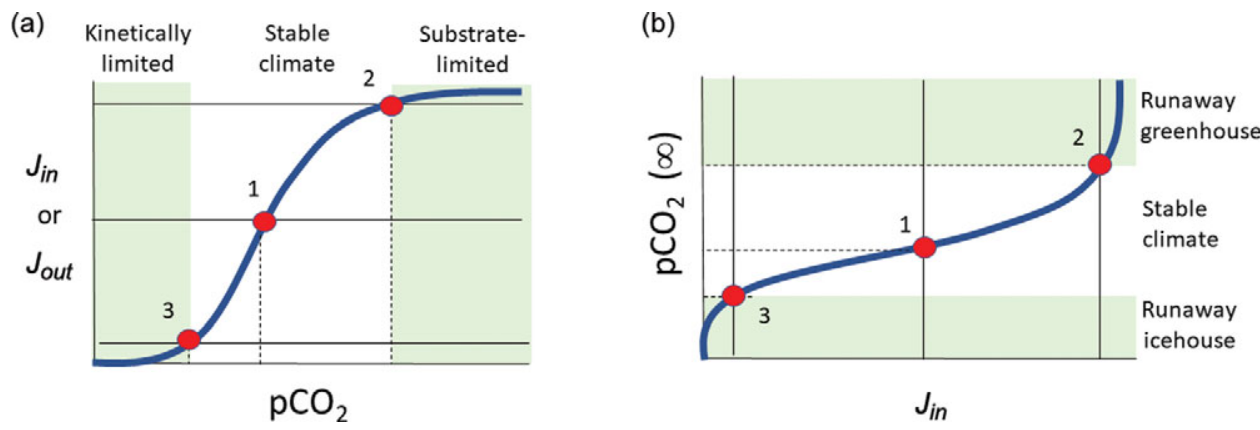

Figure 11.6 (a) Input $J_{\text {in }}$ and output $J_{\text {out }}$ versus $\mathrm{pCO}_{2}$. The conceptual model is identical to that of Figure 11.5, but the functional form of the weathering feedback $J_{\text {out }}$ is nonlinear, consisting of lowsensitivity regimes at low $\mathrm{pCO}_{2}$ and high $\mathrm{pCO}_{2}$. These low-sensitivity regimes are referred to here as kinetically limited and substrate-limited, respectively. At low $\mathrm{pCO}_{2}$, temperatures are low and kinetics of dissolution are sluggish. At high $\mathrm{pCO}_{2}$, reaction is limited by the availability of new substrate for weathering. Between these two low-sensitivity regimes lies a quasi-linear highsensitivity regime, where climate is stable. Intersections of $J_{\text {in }}$ (thin horizontal lines) with $J_{\text {out }}$ (thick bold line) are denoted by red circles. (b) Steady-state $\mathrm{pCO}_{2}$ in (a) is plotted versus $J_{i n}$. When inputs rise to some threshold (e.g. from states 1 to 2), further increases in $J_{\text {in }}$ will lead to rapid rises in $\mathrm{pCO}_{2}$. Conversely, when inputs drop below some threshold (states 1 to 3 ), further decreases in $J_{i n}$ will lead to rapid declines of $\mathrm{pCO}_{2}$. Hothouse and icehouse excursions are controlled by how close the system's baseline climate is to the threshold.

(a)

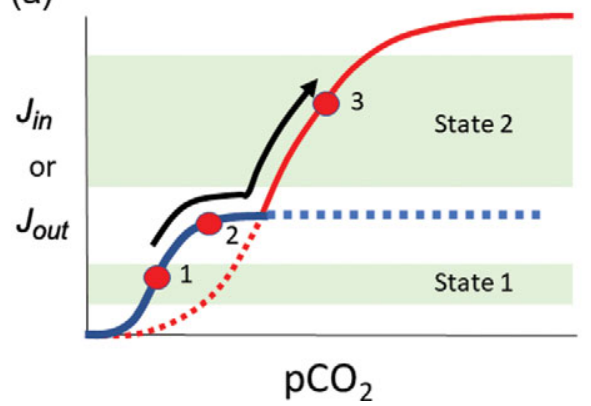

(b)

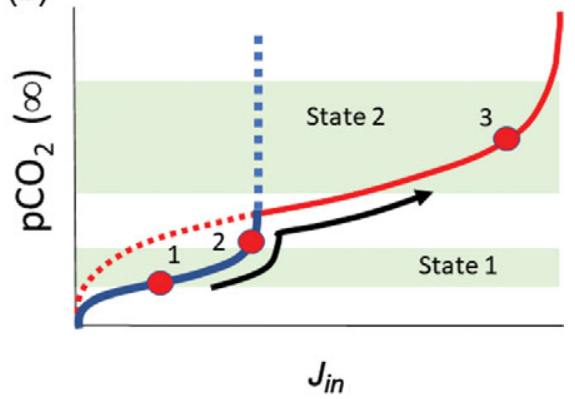

Figure 11.7 (a) and (b) are schematic diagrams that are conceptually identical to those of Figure 11.6, except that two different functional forms of the weathering feedback $J_{i n}$ are shown. The two different weathering feedback mechanisms are assumed to operate at different $\mathrm{pCO}_{2}$ values such that the system can transition into a fundamentally new state after it crosses a $\mathrm{pCO}_{2}$ threshold (e.g. from states 1 to 2 to 3 ).

\subsection{Carbon Inventories of Earth Reservoirs}

\subsubsection{Modern and Primitive Mantle Reservoirs}

Excluding the core, more than $99.99 \%$ of all C on Earth is in the mantle and crust, although exact quantities are highly uncertain. ${ }^{18}$ Estimates of the $\mathrm{C}$ budget of the uppermost mantle are 
Table 11.1 Reservoirs of carbon

\begin{tabular}{|c|c|c|c|}
\hline Reservoirs & Concentration & Gton C & Refs. \\
\hline Atmosphere & 278 ppmv & 590 & \\
\hline Oceans & & $(3.7-3.9) \times 10^{4}$ & {$[12,13]$} \\
\hline Surface layer - inorganic & & $700-900$ & {$[13,14]$} \\
\hline Deep layer - inorganic & & $(3.6-3.8) \times 10^{4}$ & {$[12,14]$} \\
\hline Total organic & & $600-700$ & {$[15,16]$} \\
\hline Reactive marine sediment & & 3150 & {$[12]$} \\
\hline Inorganic & & 2500 & {$[12]$} \\
\hline Organic & & 650 & {$[12]$} \\
\hline $\begin{array}{l}\text { Terrestrial biosphere } \\
\text { and soils }\end{array}$ & & $(2-2.3) \times 10^{3}$ & {$[12,14]$} \\
\hline Vegetation & & $500-600$ & {$[12]$} \\
\hline Soil & & $(1.5-1.7) \times 10^{3}$ & {$[12]$} \\
\hline \multicolumn{4}{|l|}{ Continental crust (CC) } \\
\hline Total CC & & $4.2 \times 10^{7}$ & {$[58]$} \\
\hline Total CC & & $2.6 \times 10^{8}$ & [59] \\
\hline $\begin{array}{l}\text { Sedimentary (carbonate }+ \\
\text { organic C) }\end{array}$ & & $3.4 \times 10^{7}$ & {$[58]$} \\
\hline $\begin{array}{l}\text { Igneous and metamorphic } \\
\text { rocks }\end{array}$ & & $0.8 \times 10^{7}$ & {$[58]$} \\
\hline $\begin{array}{l}\text { Continental lithospheric } \\
\text { mantle }\end{array}$ & $<760$ ppm & $<4.8 \times 10^{7}$ & $\begin{array}{l}\text { This study }(=\mathrm{BSE}-\mathrm{CC}- \\
\text { DM - ROL) }\end{array}$ \\
\hline Oceanic crust and & & $1.4 \times 10^{7}$ & {$[18]$} \\
\hline \multicolumn{4}{|l|}{ lithospheric mantle } \\
\hline \multicolumn{4}{|l|}{ Mantle (total) } \\
\hline $\mathrm{DM}(<670 \mathrm{~km})$ & 30 ppm C & $3.2 \times 10^{7}$ & [19] \\
\hline $\begin{array}{l}\text { Upper mantle (assuming BSE } \\
\text { composition) }\end{array}$ & $<350$ ppm C & $<3.7 \times 10^{8}$ & This study \\
\hline $\begin{array}{l}\text { Lower mantle (assuming BSE } \\
\text { composition) }\end{array}$ & $<350$ ppm C & $<1.0 \times 10^{9}$ & This study \\
\hline BSE & $<350$ ppm C & $<1.4 \times 10^{9}$ & This study \\
\hline Fossil fuel reserves & & $5 \times 10^{3}$ & {$[12]$} \\
\hline
\end{tabular}

BSE = bulk silicate Earth; DM = depleted mantle; ROL = recycled oceanic lithosphere.

indirectly calculated from the $\mathrm{C}$ content of mid-ocean ridge basalts (MORBs), with $\mathrm{C}$ itself inferred by bootstrapping to other elements, such as $\mathrm{Nb}, \mathrm{Ba}, \mathrm{H}$, or noble gases. ${ }^{37-39}$ These studies have resulted in estimates of 16-300 ppm C for the MORB source mantle, typically assumed to represent the upper mantle (Figure 11.3). However, reconstructing mantle $\mathrm{C}$ contents is faced with the challenge of correcting for degassing of $\mathrm{C}$ and other elements. Tucker et al. ${ }^{19}$ and Hauri et al. (Chapter 9 of this book) provide the most recent and rigorous reconstructions of the MORB source region and arrive at $30 \mathrm{ppm} \mathrm{C}$ (Table 11.1). This estimate 

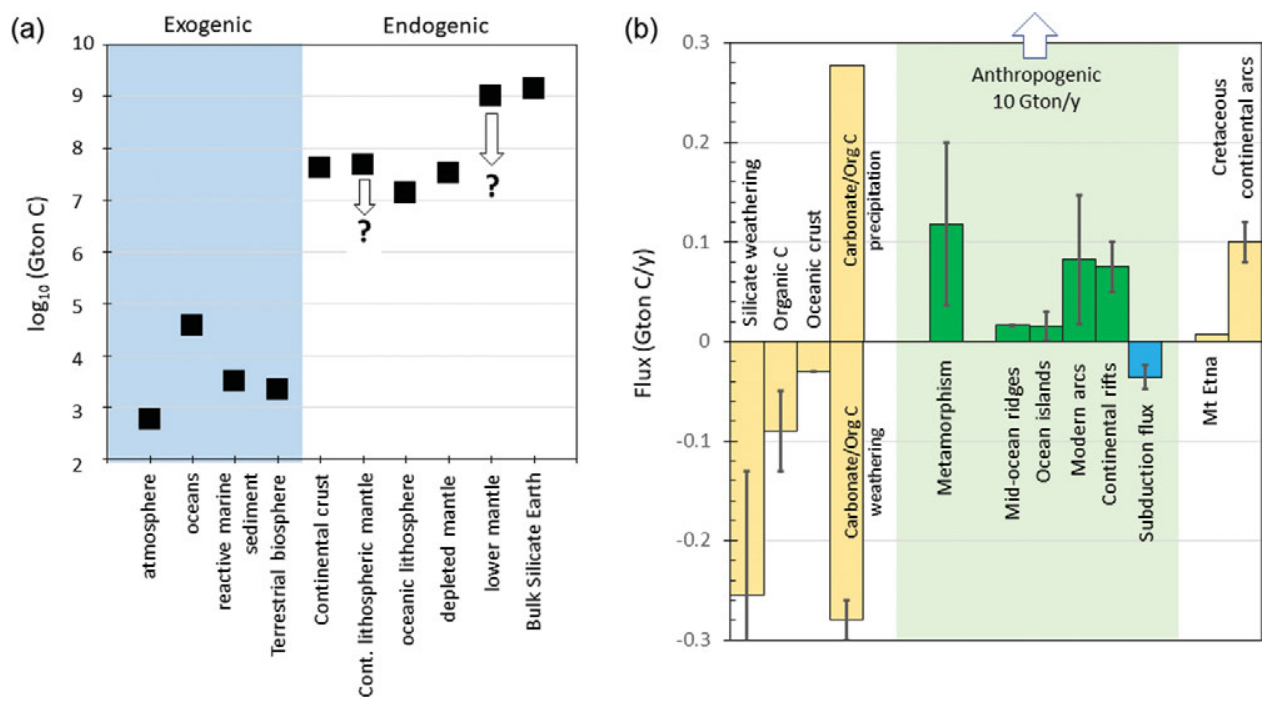

Figure 11.8 (a) Estimates of total $\mathrm{C}$ content (Gton C) in various exogenic and endogenic reservoirs. See Table 11.1 and text for details. Estimates of the continental lithospheric mantle and bulk silicate Earth (BSE) are from this study. Downward-pointing arrows denote that these estimates represent maximum bounds. Depleted mantle volume corresponds to mantle above $670 \mathrm{~km}$ with $\mathrm{C}$ concentration equal to that inferred for the MORB mantle source. Lower mantle corresponds to mantle between $670 \mathrm{~km}$ and the core-mantle boundary with a $\mathrm{C}$ concentration equivalent to BSE. (b) Graphical representation of $\mathrm{C}$ fluxes (Gton $\mathrm{C} / \mathrm{y}$ ) with inputs as positive values and outputs as negative values. Silicate weathering, organic $\mathrm{C}$ burial, and seafloor weathering are shown in yellow. Inputs of $\mathrm{CO}_{2}$ via weathering of organic $\mathrm{C}$ and carbonates are combined (negative bars), but such weathering is thought to be balanced by rapid re-precipitation of carbonate and burial of organic carbon (positive bars). Endogenic outgassing is shown in green, while subduction is shown in blue. Degassing through Mt. Etna and Cretaceous continental arcs is shown in order to illustrate the importance of carbonate-intersecting continental arcs. Vertical arrow points to anthropogenic production of $\mathrm{CO}_{2}$ through fossil fuel burning and cement production (10 Gton $\mathrm{C} / \mathrm{y}$ ).

agrees well with previous estimates of $\sim 15-50 \mathrm{ppm}$ C for the MORB source mantle that used undegassed or minimally degassed MORB $\mathrm{CO}_{2}$ contents and $\mathrm{CO}_{2} / \mathrm{Ba}, \mathrm{CO}_{2} / \mathrm{Nb}$, and $\mathrm{H} / \mathrm{C}$ ratios (e.g. Refs. 37, 38, 40, and 41). A homogeneous upper mantle $(<670 \mathrm{~km}$; mass of $1.06 \times 10^{24} \mathrm{~kg}^{42}$ ) with a MORB source $\mathrm{C}$ content would contain $\sim 3.2 \times 10^{7}$ Gton $\mathrm{C}$ (Figure 11.8). If the MORB source was representative of the entire mantle down to the core-mantle boundary $\left(4.0 \times 10^{24} \mathrm{~kg}\right)$, the whole mantle would contain $1.2 \times 10^{8}$ Gton $\mathrm{C}$.

Of interest is the $\mathrm{C}$ content of the bulk silicate Earth (BSE), which is the primordial mantle prior to extraction of the continents, oceans, and atmosphere (Figure 11.9a). The present mantle represents what remains of the mantle after degassing and silicate differentiation, which we refer to as the Depleted Mantle (DM); the composition of the DM is assumed to be represented by the MORB source mantle. ${ }^{43,44}$ Thus, the BSE can be calculated by re-homogenizing the atmosphere, oceans, and continents back into the $\mathrm{DM}$, but this is challenging if the $\mathrm{C}$ contents of all of these reservoirs and their sizes are 
(a)

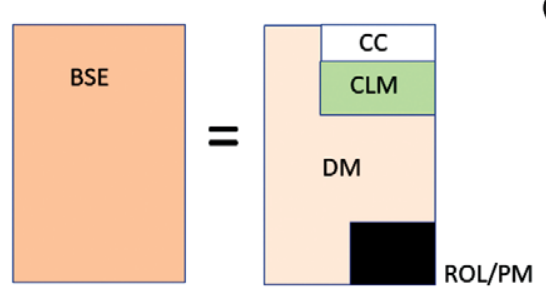

(c)

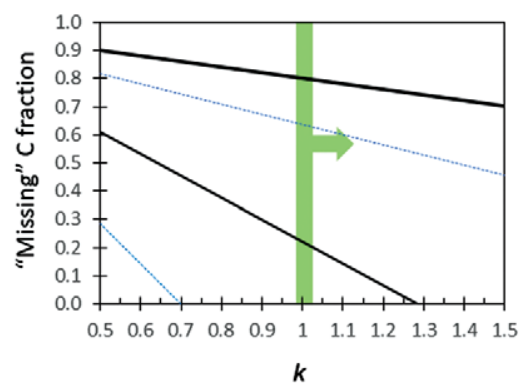

(b)

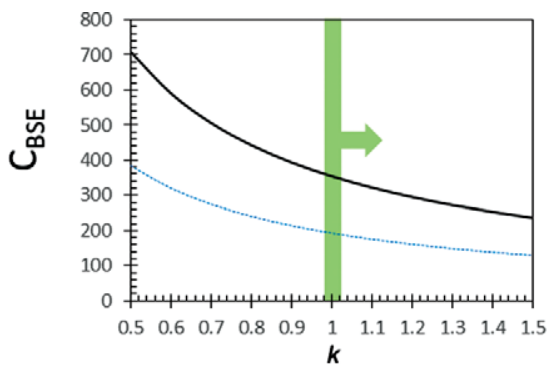

(d)

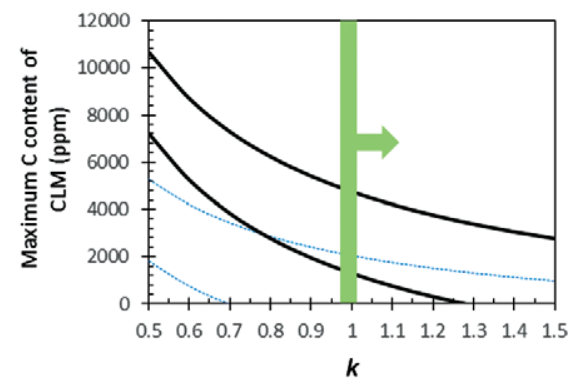

Figure 11.9 (a) Cartoon showing how C concentration in BSE is determined. BSE is the hypothetical primordial mantle composition after combining the DM, continental crust (CC), continental lithospheric mantle (CLM), and all other reservoirs, such as recycled oceanic lithosphere (ROL), as well as oceans, atmosphere, etc. (latter not shown because of small size). (b) C content of BSE as constrained by relative depletion of $\mathrm{Ba}$ and $\mathrm{U}$ in DM. Horizontal axis represents the relative efficiency $k$ by which $\mathrm{C}$ is retained (during melting) or recycled (during subduction) into the mantle compared to $\mathrm{Ba}$ or $\mathrm{U} ; k$ is likely larger than 1. (c) Missing fraction of $\mathrm{C}$ from the DM after subtraction of $\mathrm{C}$ in continental crust (DM is assumed to be the size of the upper mantle down to $670 \mathrm{~km}$ ). Thick black lines correspond to estimates based on C/Ba-constrained BSE and thin blues lines are based on C/U-constrained BSE. Two sets of lines for each color are denoted and correspond to calculations using the crustal budgets of $\mathrm{C}$ from Wedepohl ${ }^{58}$ and Gao et al. ${ }^{59}$ This missing $\mathrm{C}$ can be stored in the CLM or as recycled components in the mantle. (d) Maximum concentration of $\mathrm{C}$ in CLM, assuming all missing C is the CLM.

not known well. A common approach, used for refractory lithophile elements, is to extrapolate magmatic differentiation trends to chondritic ratios, but this cannot be done for $\mathrm{C}$ because of its volatility during nebular condensation/planetary accretion and siderophile nature during core formation (e.g. Ref. 45).

Instead, we infer the $\mathrm{C}$ of BSE from elements that behave geochemically like $\mathrm{C}$ but are refractory in a cosmochemical sense. For example, during mantle melting, $\mathrm{C}$ is thought to behave like Ba, a refractory element. ${ }^{19,41}$ The depletion of $\mathrm{Ba}$ in the $\mathrm{DM}\left(0.563 \mathrm{ppm}^{46}\right)$ relative to the $\mathrm{BSE}\left(6.6 \mathrm{ppm}^{47}\right)$ - that is, $\mathrm{Ba}_{\mathrm{DM}} / \mathrm{Ba}_{\mathrm{BSE}}-$ is $\sim 0.085$. If $\mathrm{Ba}$ and $\mathrm{C}$ also behave similarly during subduction, then the relative depletion of $\mathrm{C}$ in the MORB source is equivalent to that of $\mathrm{Ba}$. The $\mathrm{BSE}$ concentration of $\mathrm{C}$ is then calculated by dividing the $\mathrm{C}$ concentration of the $\mathrm{DM}$ by the $\mathrm{Ba}$ depletion factor $\left(\mathrm{C}_{\mathrm{BSE}}=\mathrm{C}_{\mathrm{DM}} /\left(\mathrm{Ba}_{\mathrm{DM}} / \mathrm{Ba}_{\mathrm{BSE}}\right)\right.$ ), yielding $\sim 350 \mathrm{ppm} \mathrm{C}$ for the $\mathrm{BSE}$ (Figure $11.9 \mathrm{~b}$ ). If $\mathrm{C}$ does not behave identically to $\mathrm{Ba}$, 
then a correction factor must be applied, $\mathrm{C}_{\mathrm{BSE}}=\mathrm{C}_{\mathrm{DM}} /\left(k_{\mathrm{C} / \mathrm{Ba}} \times \mathrm{Ba}_{\mathrm{DM}} / \mathrm{Ba}_{\mathrm{BSE}}\right)$, where $k_{\mathrm{C} / \mathrm{Ba}}$ represents the efficiency by which $\mathrm{C}$ is returned to the mantle relative to $\mathrm{Ba}$ (or the relative efficiency by which $\mathrm{C}$ is retained or recycled into the mantle relative to $\mathrm{Ba}$ ). If $k_{\mathrm{C} / \mathrm{Ba}}>1$, $\mathrm{C}$ is preferentially subducted deep into the mantle relative to $\mathrm{Ba}$ and our estimates of $\mathrm{C}$ in the $\mathrm{BSE}$ are hard maximum bounds. If $k_{\mathrm{C} / \mathrm{Ba}}<1, \mathrm{Ba}$ is preferentially recycled and our estimates are minimum bounds (Figure $11.9 \mathrm{~b}$ ). It seems likely that $\mathrm{Ba}$, mostly concentrated in slab sediments, is more efficiently removed from the subducting slab given the extreme enrichments of $\mathrm{Ba}$ in arc lavas. ${ }^{48}$ While some of the carbonate in subducting sediments might also be removed efficiently, ${ }^{49}$ organic $\mathrm{C}$ and carbonate in the oceanic crust are likely retained, ${ }^{50,51}$ so it seems likely that $k_{\mathrm{C} / \mathrm{Ba}}>1$, and thus $\mathrm{C}_{\mathrm{BSE}}<350 \mathrm{ppm}$. If $\mathrm{C}$ during melting behaves more like $\mathrm{U}$, a refractory element with a DM depletion factor of $\sim 0.16$ relative to BSE (Figure 11.9b), ${ }^{46} \mathrm{C}_{\mathrm{BSE}}<\sim 192 \mathrm{ppm}$. In any case, $\mathrm{C}_{\mathrm{BSE}}$ can be no higher than $<350 \mathrm{ppm}$ (Table 11.1), consistent with a recent estimate of $\mathrm{C}_{\mathrm{BSE}}$ of $\sim 140 \mathrm{ppm} .{ }^{52}$ These values of $C_{B S E}$ would imply that the DM reservoir has lost no more than $40-90 \%$ of its original $\mathrm{C}$ during silicate differentiation; however, the DM reservoir is unlikely to represent the entire convecting mantle, so the fractional loss of $\mathrm{C}$ from the whole mantle must be far smaller. We note that the $\mathrm{C}$ concentration of the mantle source of ocean island basalts (OIBs) ranges from 33 to $500 \mathrm{ppm} \mathrm{C.}{ }^{18}$ The source region of OIBs is thought to represent primitive undegassed mantle and/or enriched domains associated with recycled crust. $^{53,54}$

\subsubsection{Continental Crust and Continental Lithospheric Mantle}

Carbon in the continental crust is represented by ancient sedimentary rocks as well as carbonate and graphite stored in metamorphic and igneous basement rocks. The sedimentary rocks are dominated by carbonates (limestones and dolostones) with organic C-rich sediments making up a smaller fraction. ${ }^{55,56}$ The carbonate content of the continental crust is calculated by estimating the volume of carbonate sediments in the continents. ${ }^{57,58}$ Due to high variability in the organic $\mathrm{C}$ content of sediments, the average organic $\mathrm{C}$ content of continents is usually estimated by assuming that organic $\mathrm{C}$ makes up $\sim 20 \%$ of the total $\mathrm{C}$ budget. This approach is based on the assumption that the $\mathrm{C}$ isotopic composition of seawater, often assumed to represent the fraction of organic $\mathrm{C}\left(f_{\text {org }}\right)$, has remained relatively constant over most of Earth's history. The $\mathrm{C}$ content of the rest of the continental crust is estimated from measurements of basement rocks and extrapolated to the upper, middle, and lower crusts based on a model of the compositional structure of the crust. Because of the high degree of variability in carbonate content of igneous and metamorphic rocks, any estimate of the $\mathrm{C}$ content of the nonsedimentary part of the continental crust is fraught with large errors. For example, Wedepohl ${ }^{58}$ estimated that the continental basement amounted to one-fifth of the $\mathrm{C}$ in sedimentary rocks, yielding a total continental crust budget of $4.2 \times 10^{7}$ Gton C. A more comprehensive study of basement rocks in China found higher concentrations of $\mathrm{C}$ in igneous and metamorphic rocks, leading to a much higher estimate of the total continental crust budget of $2.6 \times 10^{8}$ Gton C. $^{59}$ 
We now turn to the continental lithospheric mantle (CLM), the cold and hence rheologically strong part of the mantle underlying the continental crust, which extends down to depths of $\sim 100 \mathrm{~km}$ beneath Phanerozoic terranes and up to $200-250 \mathrm{~km}$ beneath many stable cratons. ${ }^{60-63}$ Because of their Gy stability, ${ }^{64-67}$ CLM is subjected to numerous metasomatic events, which could lead to hydration or carbonation. ${ }^{68-75}$ We can place an upper bound on how much C could be in the CLM. If we assume that the volume of DM is equivalent to the entire upper mantle down to $670 \mathrm{~km}$ depth $\left(1.06 \times 10^{24} \mathrm{~kg}\right)$, the total amount of $\mathrm{C}$ degassed is $<3.4 \times 10^{8}$ Gton $\mathrm{C}$ as inferred above from $\mathrm{C} / \mathrm{Ba}$ systematics and $>1.7 \times 10^{8}$ Gton $\mathrm{C}$ from $\mathrm{C} / \mathrm{U}$ systematics. From these quantities we subtract the amount of $\mathrm{C}$ in the continental crust. If we use the higher crustal abundances of Gao et al. ${ }^{59}$ and the DM C content inferred from $\mathrm{C} / \mathrm{Ba}$, we are left with $20 \%$ of unaccounted $\mathrm{C}$ that must be housed in the CLM or as recycled components deep in the mantle (Figure 11.9c). If we use the crustal abundances of Wedepohl, ${ }^{58} 80 \%$ is unaccounted for. If we use the lower estimates of $\mathrm{C}$ in $\mathrm{DM}$ as inferred from $\mathrm{C} / \mathrm{U}$ systematics, we find that the $\mathrm{C}$ budget of the continental crust accounts for or even exceeds the amount of $\mathrm{C}$ degassed from the upper mantle, which seems unreasonable; reconciling this discrepancy would require a volume of mantle greater than the upper mantle to have degassed to the extent of the DM reservoir. In any case, if we restrict the DM to the upper mantle and use the C/Ba-constrained DM composition and Gao et al.'s crustal estimate, we find a maximum missing C of $4.8 \times 10^{7}$ Gton C. All of this C in the CLM would translate to a hard upper bound of $\sim 740 \mathrm{ppm} \mathrm{C}$ in the CLM, assuming an average CLM thickness of $\sim 150 \mathrm{~km}$ (Figure 11.9d and Table 11.1). No doubt, some of the missing $\mathrm{C}$ is in the form of recycled crust deep in the mantle, as balancing present-day arc flux requires a small fraction of subducted $\mathrm{C}$ to be supplied to sub-arc mantle source regions via fluids or melts (e.g. Ref. 76). Whether the missing $\mathrm{C}$ is in the $\mathrm{CLM}^{49}$ or recycled into the deep mantle ${ }^{52}$ is currently debated.

\subsubsection{Exogenic Reservoirs}

For completeness, we briefly discuss the $\mathrm{C}$ budget of the exogenic system (Table 11.1). In total, the exogenic system accounts for $<0.01 \%$ of Earth's $\mathrm{C}$ budget (excluding the core), with reservoir sizes increasing as follows (Figure 11.3): atmosphere $<$ terrestrial biosphere and soil $<$ reactive marine sedimentary carbon $<$ ocean. ${ }^{11}$ For a modern preindustrial atmospheric $\mathrm{CO}_{2}$ content of 280 ppmv, the total amount of pre-anthropogenic $\mathrm{C}$ in the atmosphere today is $590 \mathrm{Gton}$ or $\sim 1.4 \%$ of the total $\mathrm{C}$ in the exogenic system. ${ }^{11}$ The oceans account for $\sim 87 \%$ of the total exogenic $\mathrm{C}$, with most of the $\mathrm{C}$ in the oceans in the form of $\mathrm{HCO}_{3}{ }^{-}$. The terrestrial biosphere and soils account for $\sim 4 \%$ and the reactive marine sedimentary reservoir accounts for $\sim 8 \%$ of the total exogenic C. It is possible that the reactive marine sedimentary reservoir is substantially larger than noted here if the size of gas-hydrate reservoirs has been underestimated. ${ }^{77}$

In summary, although the amount of $\mathrm{C}$ in the exogenic system is nearly negligible compared to that of the bulk Earth, all $\mathrm{C}$ degassed from the interior of Earth passes through 
the exogenic system before being buried as carbonates or organic $\mathrm{C}$, and it is through the exogenic system that $\mathrm{C}$ influences climate.

\subsection{Long-Term Carbon Fluxes}

\subsubsection{Inputs}

\subsubsection{Volcanic Inputs}

On long timescales, the exogenic system is supported by $\mathrm{C}$ inputs from the endogenic system through volcanism, metamorphism, and weathering of ancient carbonates and organic C. Outputs from the exogenic system occur through carbonate and organic $\mathrm{C}$ burial via the intermediate steps of silicate weathering and photosynthesis. Ultimately, some fraction of carbonate and organic $\mathrm{C}$ is removed from the exogenic system by deep burial in the crust or subduction back into the mantle (Figure 11.3).

Fluxing of $\mathrm{C}$ into and out of the exosphere can occur through many different species of $\mathrm{C}\left(\mathrm{CO}_{2}, \mathrm{CH}_{4}, \mathrm{CO}\right.$, etc.). We denote all $\mathrm{C}$ fluxing, regardless of species, in terms of Gton of elemental $\mathrm{C}$ per year. In the case of volcanism and metamorphism, the dominant $\mathrm{C}$ species today is $\mathrm{CO}_{2}$. The most widely used estimate of global volcanic degassing is that of Marty and Tolstikhin. ${ }^{78}$ Based on various approaches to estimating $\mathrm{CO}_{2}$ fluxes through midocean ridges (MORs), arcs, and intraplate magmas (Figure 11.10), they estimated a global volcanic C flux of 0.03-0.13 Gton C/y, with MORs > arcs > intraplate magmatism. These estimates are highly uncertain. In both cases, $\mathrm{C}$ fluxes were estimated by measuring $\mathrm{C} /{ }^{3} \mathrm{He}$ ratios in gases or hydrothermal plumes and then multiplying by the ${ }^{3} \mathrm{He}$ flux, which is either measured or calculated. Regardless of these uncertainties, the Marty and Tolstikhin estimates are lower bounds because they did not consider diffuse fluxes, which Burton et al. $^{21}$ showed to be significant. Burton et al. estimate that the total subaerial flux, dominated by arc volcanoes, could be as high as $0.15 \mathrm{Gton} \mathrm{C} / \mathrm{y}$, significantly greater than the $\sim 0.030$ Gton C/y arc flux estimated by Marty and Tolstikhin (Figure 11.8). Diffuse degassing through faults in continental rifts can also be important (Figure 11.10b); diffuse degassing in the East African Rift alone currently emits 0.05-0.10 Gton C/y, comparable to the flux emitted through the entire length of MORs (Figure 11.8). ${ }^{79}$ It is also important to consider that some anomalous volcanoes like Mount Etna, whose magmas have interacted with crustal carbonates, have unusually high emissions ( $0.006 \mathrm{Gton} / \mathrm{y}$ for Mount Etna $\left.{ }^{24}\right)$, with one volcano accounting for a substantial proportion $(>10 \%)$ of the modern arc flux (Figure 11.8).

Global volcanic inputs of $\mathrm{C}$ are thus at least $0.54 \mathrm{Gton} \mathrm{C} / \mathrm{y}$ if diffuse degassing estimates from Burton et al. ${ }^{21}$ are considered. Global volcanic flux of $\mathrm{C}$ through geologic time, however, is likely to vary significantly due to variations in plume activity or global oceanic crust production rates. ${ }^{80,81}$ It has also been shown that continental arcs, because of magmatic interactions (via assimilation, melt-rock reaction, contact, and regional metamorphism ${ }^{82-85}$ ) with ancient crustal carbonates stored in the continents emit significantly more $\mathrm{CO}_{2}$ than island arcs (Figure 11.10c and $\mathrm{d}$ ); hence, the waxing and waning of 

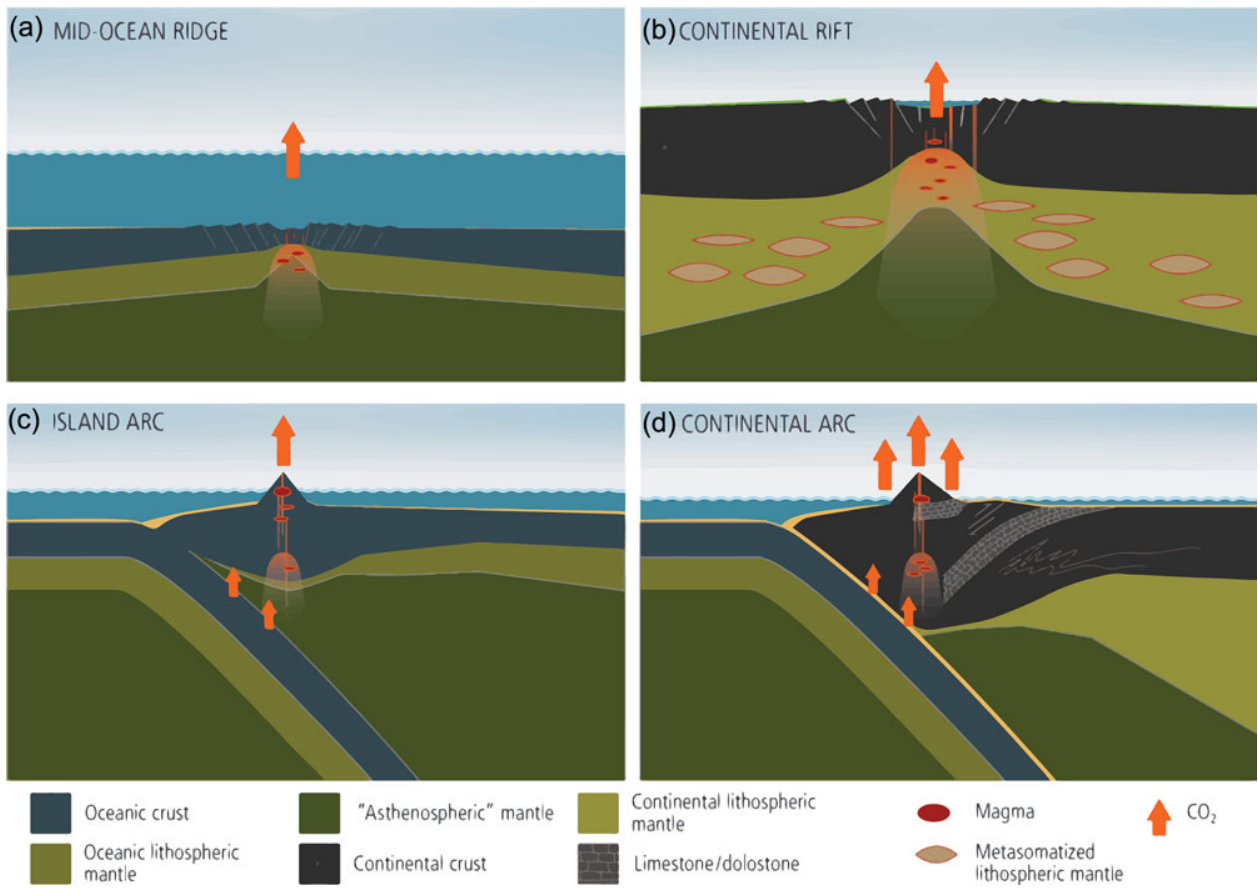

Figure 11.10 The four most important regions of magmatically related degassing (not to scale): (a) MORs, (b) continental rifts, (c) island arcs, and (d) continental arcs. In continental rifts, metasomatized domains within the CLM may contain excess $\mathrm{C}$ in the form of carbonate or graphite. Destabilization of such $\mathrm{C}$ can enhance magmatic flux during rifting. In continental arcs, magmatic degassing can be enhanced by decarbonation of crustal carbonates.

continental arcs through time will also lead to increases in volcanic $\mathrm{CO}_{2}$ fluxing. ${ }^{22,23,86-88}$ Enhanced continental rifting could also lead to enhanced $\mathrm{CO}_{2}$ production. ${ }^{79,89,90}$

\subsubsection{Metamorphic Inputs}

Metamorphic inputs of $\mathrm{C}$ involve thermal breakdown of crustal carbonates. The dominant decarbonation reactions occur by reaction of carbonate with silica:

$$
\mathrm{CaCO}_{3}+\mathrm{SiO}_{2}=\mathrm{CaSiO}_{3}+\mathrm{CO}_{2},
$$

to form calc-silicate minerals, such as wollastonite and other pyroxenes. ${ }^{91,92}$ These reactions operate at temperatures $\left(400-600^{\circ} \mathrm{C}\right)$ that can be achieved over large areas during regional metamorphism. The presence of water, which decreases $\mathrm{CO}_{2}$ activity, further decreases the temperatures needed for reaction $\left(300^{\circ} \mathrm{C}\right) .{ }^{93}$ Metamorphic decarbonation can thus be pervasive in subduction zones, continental collisions, or continental extension.

Estimates of metamorphic $\mathrm{CO}_{2}$ degassing rates, particularly on a global scale, are challenging to quantify because metamorphic degassing is diffuse and spatially heterogeneous. It has been shown that the metamorphic $\mathrm{CO}_{2}$ flux in the Himalayas may be large, 
being similar to or even higher than that removed by silicate weathering from the Himalayas themselves. ${ }^{94}$ Kerrick and Caldeira ${ }^{20}$ have suggested that metamorphic outgassing associated with orogenies during the Eocene could be anywhere between 0.04 and 0.20 Gton C/y (Figure 11.8). Importantly, even though these numbers are highly uncertain, their magnitudes are potentially equal to or greater than that of MOR degassing.

\subsubsection{Carbonate and Organic Carbon Weathering}

Weathering of ancient crustal carbonates and organic $\mathrm{C}$ represents another large input of $\mathrm{C}$ into the exogenic system. Carbonate weathering involves the dissolution of the carbonate fraction in eroding material by the following reaction

$$
\mathrm{CaCO}_{3}+\mathrm{CO}_{2}+\mathrm{H}_{2} \mathrm{O}=\mathrm{Ca}^{2+}+2 \mathrm{HCO}_{3}{ }^{-} .
$$

For each mole of $\mathrm{CO}_{2}$ consumed, dissolution releases 2 moles of bicarbonate $\left(\mathrm{HCO}_{3}{ }^{-}\right)$, resulting in a net contribution of 1 mole of $\mathrm{CO}_{2}$ to the ocean-atmosphere system. However, because carbonate dissolution introduces $\mathrm{Ca}^{2+}$ and $\mathrm{Mg}^{2+}$ ions as well as bicarbonate ion into the ocean (in silicate weathering, $\mathrm{CO}_{2}$ is consumed), precipitation of carbonate follows:

$$
\mathrm{Ca}^{2+}+2 \mathrm{HCO}_{3}{ }^{-}=\mathrm{CaCO}_{3}+\mathrm{CO}_{2}+\mathrm{H}_{2} \mathrm{O} .
$$

On timescales longer than $\sim 10 \mathrm{ky}$, carbonate dissolution and precipitation balance, such that carbonate weathering is not thought to significantly influence the long-term evolution of exogenic C. ${ }^{3}$

Another source of $\mathrm{CO}_{2}$ is weathering of organic $\mathrm{C}$, wherein a reduced form of $\mathrm{C}$ is oxidized by the atmosphere to form oxidized $\mathrm{C}$; that is, $\mathrm{CO}_{2}$ :

$$
\mathrm{O}_{2}+" \mathrm{CH}_{2} \mathrm{O} "=\mathrm{CO}_{2}+\mathrm{H}_{2} \mathrm{O} .
$$

Weathering of "black" shales would be an example of oxidative weathering of organic C. Like carbonate weathering, oxidative weathering of organic $\mathrm{C}$ is assumed to be balanced on short timescales by organic $\mathrm{C}$ burial:

$$
\mathrm{CO}_{2}+\mathrm{H}_{2} \mathrm{O}=\mathrm{O}_{2}+\text { "CH} \mathrm{CH}_{2} \mathrm{O},
$$

so that on long timescales, the net effect of organic $\mathrm{C}$ weathering on exogenic $\mathrm{C}$ is often assumed to be negligible. ${ }^{3}$ Such a close balance between organic $\mathrm{C}$ fluxes is presumably regulated by atmospheric $\mathrm{O}_{2}$ concentrations. For example, increases in the oxidative weathering of organic $\mathrm{C}$ would lead to lower atmospheric (and seawater) $\mathrm{O}_{2}$ concentrations, which are thought to enhance organic matter burial. However, there is still uncertainty as to whether the organic $\mathrm{C}$ cycle is in balance because many of the redox fluxes are not well constrained. A full treatment of organic $\mathrm{C}$ weathering must be coupled with the global oxygen cycle..$^{3,95}$

Although weathering of carbonates and organic $\mathrm{C}$ are likely balanced on timescales $>100 \mathrm{ky}$, it is nevertheless important to appreciate their magnitudes (Figure 11.8). 
The oxidative weathering rate of organic $\mathrm{C}$ is thought to be $\sim 0.05 \mathrm{Gton} \mathrm{C} / \mathrm{y},{ }^{25}$ and global compilations and river chemistry indicate a modern carbonate weathering flux of 0.148 Gton $\mathrm{C} / \mathrm{y}$ (these calculations assume stoichiometric weathering). ${ }^{17}$ Together, these fluxes are comparable to the total volcanic flux of $\mathrm{CO}_{2}$ today. To illustrate the magnitude of the carbonate weathering flux, it is now established that the alkalinity in global rivers is dominated by carbonate weathering rather than silicate weathering ${ }^{17,96,97}$ due to the fast dissolution kinetics of carbonates compared to silicates. Because these weathering fluxes are large, any imbalances in weathering of carbonates and organic $\mathrm{C}$ versus carbonates and organic $\mathrm{C}$ burial could lead to large swings in exogenic $\mathrm{C}$ on short timescales. ${ }^{98}$ The magnitudes and timescales of such swings are ultimately limited by the fact that ocean chemistry adjusts to maintain a relatively constant saturation state with respect to calcium carbonate phases. ${ }^{99}$ Estimates of the response timescale of carbonate buffering in the ocean are around 6000 years. $^{99}$ Such weathering probably cannot be truly ignored even on $>100$-ky timescales, especially if the ratio of organic $\mathrm{C}$ to carbonate weathering (or deposition) varies with time or if the distribution of carbonate and organic $\mathrm{C}$ deposition changes with time (deep sea versus continental shelves). Finally, it has recently been shown that oxidative sulfide weathering in organic-rich sedimentary rocks can lead to a net release of $\mathrm{CO}_{2}$ if the resulting sulfuric acid reacts with nearby carbonates. ${ }^{100}$ Unlike carbonate (by carbonic acid) or organic $\mathrm{C}$ weathering, sulfide weathering can serve as a long-term input of $\mathrm{CO}_{2}$ if there is an imbalance in the $\mathrm{S}$ cycle.

\subsubsection{Carbon Inputs Internal to the Exogenic System}

Geologic inputs (volcanic and weathering) of $\mathrm{CO}_{2}$ into the exogenic system are small compared to fluxes internal to the exogenic system. For context, exchange between the terrestrial biosphere and atmosphere is $\sim 60 \mathrm{Gton} \mathrm{C} / \mathrm{y}$ and between the surface ocean and atmosphere is $\sim 70 \mathrm{Gton} \mathrm{C} / \mathrm{y}$. ${ }^{11}$ Present anthropogenic $\mathrm{CO}_{2}$ emissions from fossil fuels and cement production is $\sim 10 \mathrm{Gton} \mathrm{C} / \mathrm{y},{ }^{26}$ which exceeds volcanic emissions by more than 50 times. These large fluxes are likely not important on long timescales as they operate on much faster timescales within the exogenic system. Nevertheless, on short timescales, any imbalances in the system associated with these fluxes or sources can lead to large, shortlived excursions in atmospheric $\mathrm{CO}_{2}$. Intriguingly, terrestrial biomarkers present in river sediments yield apparent radiocarbon "ages" in excess of 1000 years, ${ }^{101}$ which implies that imbalances between terrestrial photosynthesis and respiration may play a role in the exogenic $\mathrm{C}$ cycle over millennial timescales.

\subsubsection{Carbon Outputs}

\subsubsection{Silicate Weathering Chemistry and Carbonate Precipitation}

While all silicate minerals undergo dissolution, $\mathrm{Ca}$ - and $\mathrm{Mg}$-bearing silicate minerals in the continental crust (e.g. hornblende, plagioclase, pyroxene, and, to a lesser extent, olivine and biotite for $\mathrm{Mg}$ only) are often considered the most important in the context of the long- 
term global $\mathrm{C}$ cycle because the dissolved $\mathrm{Ca}^{2+}$ and $\mathrm{Mg}^{2+}$, after traveling to the ocean via rivers, eventually precipitate to form calcium and magnesium carbonates in the marine environment. However, alkalinity supplied by the dissolution of $\mathrm{Na}$ - and K-bearing silicates dominates the silicate-derived riverine flux and contributes to $\mathrm{CaCO}_{3}$ precipitation via ion-exchange reactions. Additionally, some portion of the $\mathrm{Na}$ and $\mathrm{K}$ flux is thought to react with $\mathrm{Si}$ and $\mathrm{Al}$ to form clay minerals in a process termed "reverse" weathering, which, by modifying the seawater alkalinity balance, contributes $\mathrm{CO}_{2}$ back into the atmosphere. ${ }^{102}$

The dominant Ca-bearing mineral in the average continental crust is plagioclase, but for simplicity, silicate weathering of calc-silicates is often idealized by lumping all calcsilicates into the form of wollastonite, $\mathrm{CaSiO}_{3}$ (however, wollastonite is exceedingly rare in the continental crust!). The sequence of reactions begins with formation of carbonic acid by equilibration with $\mathrm{CO}_{2}$ in the atmosphere or subsurface pore-space:

$$
\mathrm{CO}_{2}+\mathrm{H}_{2} \mathrm{O}=\mathrm{H}_{2} \mathrm{CO}_{3} .
$$

This is followed by release of $\mathrm{H}^{+}$ions:

$$
\mathrm{H}_{2} \mathrm{CO}_{3}=\mathrm{H}^{+}+\mathrm{HCO}_{3}^{-} \text {, }
$$

which react with calc-silicates to release $\mathrm{Ca}^{2+}$ and $\mathrm{Si}^{4+}$ in the form of silica hydroxides into river waters (an identical reaction can be written for $\mathrm{MgSiO}_{3}$ ):

$$
\mathrm{CaSiO}_{3}+2 \mathrm{H}^{+}+\mathrm{H}_{2} \mathrm{O}=\mathrm{Ca}^{2+}+\mathrm{Si}(\mathrm{OH})_{4} .
$$

$\mathrm{Ca}^{2+}$ ions combine with the major carbonate species in seawater, bicarbonate $\left(\mathrm{HCO}_{3}{ }^{-}\right)$, to precipitate calcium carbonate in the marine or lacustrine environments (and dissolved silica precipitates as chert, $\mathrm{SiO}_{2}$ ):

$$
\mathrm{Ca}^{2+}+2 \mathrm{HCO}_{3}{ }^{-}=\mathrm{CaCO}_{3}+\mathrm{CO}_{2}+\mathrm{H}_{2} \mathrm{O} .
$$

If we combine the above equations, we arrive at the commonly cited net reaction for calcsilicate weathering:

$$
\mathrm{CaSiO}_{3}+\mathrm{CO}_{2}=\mathrm{CaCO}_{3}+\mathrm{SiO}_{2} .
$$

The equivalent reaction for plagioclase is:

$$
\mathrm{CaAl}_{2} \mathrm{Si}_{2} \mathrm{O}_{8}+\mathrm{H}_{2} \mathrm{CO}_{3}+3 \mathrm{H}_{2} \mathrm{O}=\mathrm{CaCO}_{3}+\mathrm{Al}_{2} \mathrm{Si}_{2} \mathrm{O}_{5}(\mathrm{OH})_{4} .
$$

Dissolution of calc-silicates followed by precipitation of carbonates results in net consumption of $\mathrm{CO}_{2}$. Estimates of the terrestrial silicate weathering output of $\mathrm{C}$ in the form of carbonate are typically drawn from the dissolved flux of cations in river waters, assuming that most of the $\mathrm{Ca}$ and $\mathrm{Mg}$ ions and some portion of the $\mathrm{Na}$ and $\mathrm{K}$ fluxes (via exchange) eventually precipitate as $\mathrm{Ca}-\mathrm{Mg}$ carbonates. Modern carbonate burial fluxes associated with silicate weathering only are thought to be between 0.13 and 0.38 Gton C/y (Figure 11.8). ${ }^{11}$ As discussed above, a fraction of the $\mathrm{Ca}$ ion flux in rivers comes from dissolution of carbonate, so the carbonate fraction must be subtracted. According to 
Gaillardet et al., ${ }^{17}$ the global terrestrial carbonate-corrected silicate weathering flux may be on the low end of the above range, at $\sim 0.14 \mathrm{Gton} \mathrm{C} / \mathrm{y}$. Newer estimates from Moon et al. ${ }^{103}$ revise the silicate weathering flux to even lower values $(0.09 \pm 0.02 \mathrm{Gton} \mathrm{C} / \mathrm{y})$, but completely exclude $\mathrm{Na}$ and $\mathrm{K}$ from these calculations.

Not accounted for in the above estimates of the silicate weathering-carbonate precipitation flux is the role of seafloor basalt alteration. A number of studies have shown that the $\mathrm{CO}_{2}$ content of altered oceanic crust can be quite high. For example, Mesozoic-aged altered oceanic crust can contain up to $2.5 \mathrm{wt} . \% \mathrm{CO}_{2}$, compared to $\sim 0.5 \mathrm{wt} . \% \mathrm{CO}_{2}$ in late Cenozoic oceanic crust. ${ }^{104-107}$ These studies estimate that $\mathrm{C}$ sequestration via seafloor alteration could amount to $0.006-0.036$ Gton $\mathrm{C} / \mathrm{y},{ }^{104,107,108}$ similar to modern inputs of $\mathrm{C}$ via MORs, but less than the terrestrial silicate weathering sink (Figure 11.8).

\subsubsection{Photosynthesis and Organic Carbon Burial}

Most of the $\mathrm{C}$ in the atmosphere-ocean system today is in an oxidized form. A fraction of this $\mathrm{C}$ is reduced through autotrophic organisms by oxygenic photosynthesis to form organic C (other types of photosynthesis could have dominated early in Earth's history):

$$
\mathrm{CO}_{2}+\mathrm{H}_{2} \mathrm{O}+\text { sun's energy }=" \mathrm{CH}_{2} \mathrm{O} "+\mathrm{O}_{2} \text {. }
$$

Here, organic $\mathrm{C}$ is approximated as " $\mathrm{CH}_{2} \mathrm{O}$ " and differs from $\mathrm{CO}_{2}$ in being composed of reduced $\mathrm{C}\left(\mathrm{C}^{3+}\right.$ or less $)$ as compared to oxidized $\mathrm{C}$ in $\mathrm{CO}_{2}\left(\mathrm{C}^{4+}\right)$. Much of the organic $\mathrm{C}$ is respired (oxidized) back to the atmosphere through organic $\mathrm{C}$ decomposition or indirectly through consumption by heterotrophic life, reversing the above reaction. In net, photosynthetic production and oxidative destruction of organic $\mathrm{C}$ are roughly in balance, even on timescales as short as years or even days in some cases. However, a small fraction of organic C "leaks" out from the exogenic system through sedimentary burial. This burial of organic C, like the burial of carbonate, represents a net long-term sink of $\mathrm{C}$ from the exogenic system, but differs from the carbonate cycle in that burial of organic $\mathrm{C}$ also generates free $\mathrm{O}_{2}$, with implications for atmospheric oxygenation. Buried at great enough depths, organic $\mathrm{C}$ becomes part of the crustal reservoir in the form of "fossil" C.

Estimates of the organic $\mathrm{C}$ burial rate are typically inferred from the $\mathrm{C}$ isotopic composition of seawater. Carbon isotopes are fractionated to light values during photosynthesis but are not strongly fractionated during carbonate precipitation (due to a lack of redox change). Assuming the isotopic compositions of long-term $\mathrm{C}$ inputs into the exogenic system are mantle-like, the fraction of organic $\mathrm{C}$ (commonly referred to as $f_{\text {org }}$ in the literature) buried can be estimated from the $\mathrm{C}$ isotopic composition of seawater or marine carbonates. Except for short-term excursions, the ${ }^{13} \mathrm{C} /{ }^{12} \mathrm{C}$ of seawater has remained relatively constant at $4-5$ per mil higher than the mantle for most of Earth's history, which translates into an organic $\mathrm{C}$ burial fraction of $\sim 20-25 \%$ relative to total $\mathrm{C}$ burial (carbonate + organic C). ${ }^{3,9,109}$

Whether $f_{\text {org }}$ has indeed remained constant and, if so, why, remain important questions. ${ }^{110}$ It may be worth exploring whether the isotopic offset between inorganic and organic C remains constant through Earth's history. There is also the possibility that the 
weathering of carbonates or the metamorphic outgassing efficiencies of crustal carbonates and organic $\mathrm{C}$ are different enough that the isotopic composition of the long-term inputs of $\mathrm{C}$ into the exogenic system need not balance with mantle-like values at all times. ${ }^{22,86,111}$

\subsubsection{Subduction Flux}

Subduction of the oceanic lithosphere and accompanying marine sediments is the primary mechanism by which $\mathrm{C}$ is "permanently" removed from Earth's surface and recycled back into the endogenic system. Subduction itself is not a direct negative feedback in the climate system because it only serves to transport already sequestered $\mathrm{C}$ into the mantle. Subduction plays an indirect role in the longer-term exogenic $\mathrm{C}$ cycle and climate if it contributes some of its $\mathrm{C}$ to arc magmas or it influences the efficiency of $\mathrm{C}$ released from the sub-arc mantle wedge and into arc magmas.

Based on estimates of the carbonate and organic $\mathrm{C}$ distribution of marine sediments and the amount of $\mathrm{C}$ in seafloor altered crust (mostly in the form of carbonate), ${ }^{104,105,107,112}$ Dasgupta and Hirschmann ${ }^{18}$ estimated a modern global subduction flux of 0.024-0.048 Gton C/y (Figure 11.8). This is comparable to the lower end of estimates of global magmatic degassing. How much of this subducted $\mathrm{C}$ is released back into the crust or atmosphere through volcanism and how much continues deep down into the mantle is debated. Because the temperature needed for decarbonation reactions increases with pressure, the subducting slab needs to heat up sufficiently for efficient decarbonation. ${ }^{113,114}$ In the absence water, slab decarbonation (either during subsolidus conditions or during partial melting) is not expected to be efficient in most modern subduction zones, except for perhaps the youngest and hottest ones. ${ }^{51,114}$ Slab decarbonation would have been more efficient in the Archean if the thermal states of these ancient subduction zones were higher than today. ${ }^{51}$ In the presence of water, $\mathrm{CO}_{2}$ activities decrease, depressing reaction temperatures. ${ }^{92}$ Thus, dehydration of serpentine in the slab could give rise to "waterfluxed" decarbonation or carbonate dissolution, enhancing the efficiency of decarbonation (see Refs. 49 and 93). Small amounts of $\mathrm{C}$ in the form of graphitized organic $\mathrm{C}$ in slabs are still expected to survive fluid-fluxed melting (e.g. Ref. 50). In any case, release from the slab does not guarantee that such $\mathrm{C}$ quantitatively returns to the exogenic system through arc volcanoes.

\subsection{Efficiency of the Silicate Weathering Feedback}

In this section, we discuss the kinetics of silicate weathering (we ignore organic $\mathrm{C}$ burial because it is a smaller flux). The kinetics of silicate dissolution are much slower than those of carbonate precipitation in the oceans. The ocean is oversaturated in carbonate and therefore any $\mathrm{Ca}$ that enters the ocean tends to precipitate on short timescales. Thus, silicate dissolution is the rate-limiting step. The rate (moles/y) of dissolution should scale as ${ }^{115,116}$ :

$$
r=k A\left(a_{\mathrm{H}^{+}}\right)^{n},
$$


where $k$ is a kinetic rate constant (moles $/ \mathrm{m}^{2} / \mathrm{y}$ ) defined relative to a specified surface area $A$ (e.g. geometric or total surface area) and represents a measure of the efficiency of dissolution, $a_{\mathrm{H}^{+}}$is the activity of hydronium ions in solution, and $n$ represents the order of the chemical reaction. Hydronium ion activity $a_{\mathrm{H}^{+}}$depends on the $\mathrm{pCO}_{2}$ in equilibrium with weathering fluids:

$$
K_{1}=\frac{\mathrm{p}_{\mathrm{CO}_{2}}}{a_{\mathrm{H}^{+}} a_{\mathrm{HCO}_{3}^{-}}} .
$$

This relation with $\mathrm{pCO}_{2}$ is one potential source of a negative feedback in the global $\mathrm{C}$ cycle. If the $\mathrm{pCO}_{2}$ of weathering fluids increases as the $\mathrm{pCO}_{2}$ of the atmosphere increases (e.g. via changes in primary productivity ${ }^{117}$ ), silicate dissolution rates increase, which results in more rapid removal of $\mathrm{CO}_{2}$ from the atmosphere through carbonate precipitation. In the Earth system, the global silicate weathering feedback must also include the effects of atmospheric $\mathrm{CO}_{2}$ on the hydrologic cycle, vegetation, and so forth, so (11.23) is only meant to conceptually represent the most elementary level of $\mathrm{CO}_{2}$ feedback.

Increases in $\mathrm{pCO}_{2}$ should also lead to increases in temperature due to the greenhouse effect $\left(\sim 2.4-4.8^{\circ} \mathrm{C}\right.$ per doubling of $\left.\mathrm{pCO}_{2}{ }^{118}\right)$. The negative feedback is enhanced because of the temperature dependence of the kinetics of dissolution ${ }^{119}$; that is:

$$
k=k_{o} \exp \left(-E_{A} / R T\right),
$$

where $k_{o}$ is a pre-exponent constant that depends on the type of mineral, $E_{A}$ is the activation energy for dissolution, $R$ is the gas constant, and $T$ is temperature. If $\mathrm{pCO}_{2}$ increases, temperature increases, which in turn increases dissolution rates, thereby increasing rates of $\mathrm{CO}_{2}$ drawdown by silicate weathering (followed by carbonate precipitation).

As we scale up from the mineral to the global scale, additional influences on weathering rate must be considered. For example, if chemical weathering reactions occur close to thermodynamic equilibrium, weathering fluxes will scale with the total water flux through the system. ${ }^{120}$ Chemical weathering can also be enhanced by biology, through bioturbation and higher subsurface $\mathrm{pCO}_{2}$ levels. Because hydrology and biology can both accelerate chemical weathering, these processes can act as negative feedbacks if increases in global temperature, perhaps driven by increases in atmospheric $\mathrm{CO}_{2}$, accelerate the hydrologic cycle. ${ }^{120,121}$ Finally, chemical weathering can also be limited by the rate at which fresh rock is supplied by physical weathering and erosion. Erosion can behave as a negative feedback under conditions in which erosion is accelerated by higher hydrologic or biological activity. Under conditions in which erosion is largely controlled by tectonics, which do not depend on climate, the feedback would be poor.

Combining all of these factors results in a complicated functional form of the silicate weathering feedback. Berner ${ }^{122}$ proposed the following generalized empirical equation:

$$
F_{S i}{ }^{\prime}=f_{w}\left(\mathrm{p}_{\mathrm{CO}_{2}}\right) f_{r f}(t) f_{p l}(t) f_{r o}(t)
$$

where $F_{S i}{ }^{\prime}$ represents the silicate weathering flux contributing to carbonate precipitation, $f_{w}$ is the function describing the sensitivity of mineral dissolution to $\mathrm{pCO}_{2}, f_{r f}$ represents mean 
global relief, $f_{p l}$ represents the effect of plants, and $f_{r o}$ represents average water runoff, with all functions normalized to present conditions. In the Berner model, the temperature effect is subsumed into the effect of temperature on runoff and the effect of $\mathrm{pCO}_{2}$ on chemical weathering. For the purposes of this chapter, the exact functional relationships are not critical (see Ref. 123). These relationships must be calibrated against field studies to be relevant for a particular region or a given time period in Earth's history.

If we consider $f_{w}, f_{p l}$, and $f_{r o}$ to all be related to $\mathrm{pCO}_{2}$ through a series of transfer functions, we can combine them into one master function $f_{w}^{*}$, which describes the dependency of weathering on $\mathrm{pCO}_{2}$ :

$$
F_{S i}{ }^{\prime}=f_{w}^{*}\left(\mathrm{p}_{\mathrm{CO}_{2}}\right) f_{r f} \text {. }
$$

This leaves the relief term in Berner's model, $f_{r f}$, as the only function independent of $\mathrm{pCO}_{2}$. The relief term is fundamental as it relates to erosion rate. Erosion supplies fresh rock to the surface so that it can undergo chemical weathering. At low erosion rates, soil mantles, although chemically depleted due to their long residence times in the weathering regime, no longer contain weatherable minerals. On long timescales, what ultimately drives erosion is topography, which itself is driven by tectonism or magmatism.

We can describe $f_{r f}$ as the weighted average flux of fresh rock supplied by erosion relative to the global mean today:

$$
f_{r f}=\frac{\sum E_{i} A_{i}}{\sum E_{i}^{o} A_{i}^{o}},
$$

where $E_{i}$ is the erosion rate $(\mathrm{m} / \mathrm{y})$ in a given region $i$ and $A_{i}$ is the map area of region $i$, with the quantities in the denominator representing present-day conditions (Figure 11.11). The summation signs denote summation over the entire continental area. What is important is that the area of orogenic activity on Earth is not constant. For example, the hypothesis that mid-Cenozoic cooling was triggered by enhanced erosion associated with the Himalayan orogeny is based on the premise that the mean area of orogenies and mean erosion rates increased. ${ }^{124,125}$ A simple way to understand the effect of increased orogenic belts is to consider the case in which the silicate weathering response to changes in $\mathrm{pCO}_{2}$ is linear. In such a scenario, doubling the length of orogenic belts (i.e. doubling the mass of silicate minerals exposed at the surface per unit time) would increase the sensitivity (e.g. the slope on the silicate weathering-driven burial rate of carbonate versus $\mathrm{pCO}_{2}$ ) of the global silicate weathering feedback by a factor of 2 (Figure 11.11). If long-term inputs of $\mathrm{CO}_{2}$ into the exogenic system do not change, exogenic $\mathrm{CO}_{2}$ would decrease by a factor of 2 , cooling the atmosphere. This simple exercise also implies that in a world devoid of orogenic belts, such as in the extreme case of flat continents riding near sea level, the strength of the negative silicate weathering feedback would be substantially decreased.

Finally, temporal changes in the composition of the bedrock undergoing weathering can be important. It is widely agreed that the average composition of the continental crust is intermediate in composition, equivalent to the composition of a typical andesite. ${ }^{126}$ These published averages often obscure the fact that the continental crust is highly heterogeneous, 

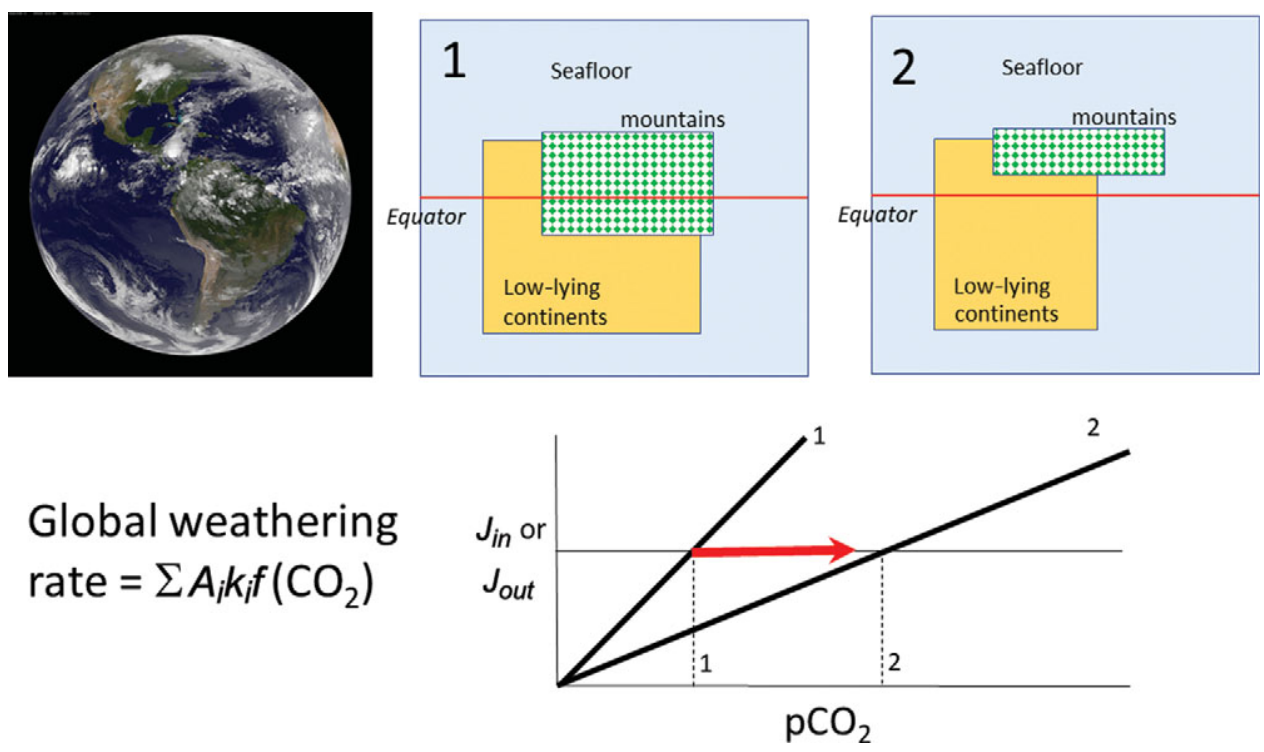

Figure 11.11 The global silicate weathering rate can be described by partitioning Earth into different types of weathering sites, each defined by different weathering kinetics (e.g. seafloor, orogens, and low-relief continents). Changes in the proportions of low-relief continents or orogenic belts will change the global sensitivity of the weathering feedback. A decrease in area of continents and orogens results in a decrease in the weathering feedback strength (states 1 to 2), leading to an increase in $\mathrm{pCO}_{2}$ (states 1 to 2 ).

containing rocks of all types, from ultramafic rocks (serpentinites and peridotites) to mafic rocks (basalts) to highly silicic rocks (e.g. rhyolites). Because different lithologies weather at different rates, have different temperature sensitivities, and supply major cations in different proportions, the composition of rocks within an active orogeny matters. For example, the $\mathrm{CaO}$ content of a typical basalt/gabbro is between 10 and $15 \mathrm{wt} \%$, that of andesite/granodiorite is between 6 and $8 \mathrm{wt} . \%$, and that of a rhyolite/granite is less than 3 wt. $\%$. Additionally, available estimates suggest that basalts weather, on average, approximately two times faster than granitic rocks, but this ratio varies as a function of climatic conditions. ${ }^{127}$ This compositional effect can be incorporated through the erosional term, $f_{r f}$ :

$$
f_{r f}=\frac{\sum E_{i} A_{i} \rho_{i} C_{i}}{\sum E_{i}^{o} A_{i}^{o} \rho_{i}^{o} C_{i}^{o}},
$$

where $C_{i}$ represents the concentration of $\mathrm{Ca}$ and $\mathrm{Mg}$ (note that not all $\mathrm{Mg}$ is sequestered as carbonate) and $\rho_{i}$ is rock density. Equation (11.28) describes the availability of $\mathrm{Ca}$ and $\mathrm{Mg}$ due to differences in composition. Depending on the composition of the crust undergoing orogeny, the sensitivity of the regional chemical weathering feedback could vary by a factor of 3-5 due to the availability of $\mathrm{Ca}$ and $\mathrm{Mg}$ (there is also a small effect of $\mathrm{Na}$ and $\mathrm{K}$ exchange with $\mathrm{Ca}$ in the ocean). Added to this compositional effect will also be the faster dissolution 
kinetics of basalt versus granite, ${ }^{17,127-129}$ which would modify $k_{i}$ in (11.22). A number of studies have shown that the composition of orogenies can vary depending on orogenic style or geologic history. ${ }^{130}$ There may have also been Gy-scale changes in the composition of magmatism, from mafic to a felsic crust around $2.5 \mathrm{Ga},{ }^{95,131,132}$ suggesting that the weathering feedback strength could have fundamentally changed over Earth's history.

In summary, silicate weathering represents a negative feedback in the whole-Earth $\mathrm{C}$ system because of the dependency of weathering on $\mathrm{pCO}_{2}$ through direct and indirect effects on temperature, biological activity, and precipitation/runoff. One of the most important controls of the strength of the feedback is the area of orogenic belts, where chemical weathering is facilitated by high erosion rates. Large fluctuations in the intensity and distribution of orogenic activity could play a key role in modulating the strength of the silicate weathering feedback.

\subsubsection{Seafloor Weathering Feedback}

In Section 11.4.2, we showed that carbonate sequestration via seafloor alteration was comparable to the $\mathrm{CO}_{2}$ flux out of MORs, begging the question of how important seafloor alteration is as a negative feedback. Coogan and Dosso ${ }^{108}$ inferred that the activation energy for rock dissolution during seafloor alteration is $\sim 92 \mathrm{~kJ} / \mathrm{mol}$, similar to that for the dissolution of various silicate minerals under conditions relevant for terrestrial weathering. ${ }^{115}$ If direct temperature effects alone were the dominant control on the negative weathering feedback, one would expect the strength of the seafloor alteration feedback to be equivalent to that of the terrestrial feedback, all other variables being equal. However, as discussed above, many other processes operate. In the case of terrestrial weathering, the effects of runoff on erosion will amplify the strength of the negative feedback. In the case of seafloor alteration, there are no erosional mechanisms that replenish fresh rock for dissolution, so the weathering system would be closer to equilibrium and the kinetics of weathering would be slow. These factors could reduce the net sensitivity of seafloor weathering to global temperature. A recent inverse study of the paleoclimate record suggested that seafloor weathering was not as important as continental weathering over the last $100 \mathrm{My} .{ }^{133}$ However, during periods of low orogenic activity, the proportional contribution of the seafloor to the global feedback indeed increases (Figure 11.11). For example, silicate weathering could have been dominated by seafloor weathering in the Archean if most of the continents were below sea level. ${ }^{134} \mathrm{In}$ such a case, the strength of the seafloor weathering feedback becomes critically important to understand.

\subsection{Discussion}

\subsubsection{Framework for Modeling Whole-Earth C Cycling}

Earth systems modeling is traditionally rendered in terms of boxes with estimates of reservoir sizes and fluxes (Figure 11.3 and Sections 11.3 and 11.4). However, in such renditions, fluxes and reservoir sizes are snapshots in time and cannot be applied back in 
time if reservoir sizes change. Instead of using fluxes, it is better to use the kinetics of C transfer between reservoirs, as kinetic rate "constants" do not depend on reservoir size even if the system is not at steady state. Rate constants can of course change if the fundamental physics and chemistry change. If the rate constants are known, (11.1) can be expressed as follows for a linear system:

$$
\frac{d M_{i}}{d t}=\sum k_{j i} M_{j}-\sum k_{i j} M_{i}
$$

where $k_{i j}$ represents the rate constant describing the transfer of $\mathrm{C}$ from reservoir $i$ to $j$. The first term represents inputs into reservoir $j$ from all reservoirs $i$. The second term represents outputs from reservoir $i$ into different reservoirs $j$. Solving (11.29) for a system of interacting reservoirs involves solving a system of equations using a multidimensional $(i \times j)$ matrix $k_{i j}$, which can be estimated from modern fluxes if the system is near steady state. We can divide the flux associated with any given process by the size of the reservoir from which $\mathrm{C}$ is removed, resulting in a fractional rate constant. The sum of all rate constants describing removal of $\mathrm{C}$ from a reservoir $i$ is the total rate constant, $k_{i}$; that is:

$$
k_{i}=\sum_{j} k_{i j} .
$$

The inverse of the total rate constant represents the residence time $\tau_{i}$ of $\mathrm{C}$ in reservoir $i$ from which $\mathrm{C}$ is extracted ${ }^{135}$ :

$$
\tau_{i}=\frac{1}{k_{i}}=\frac{1}{\sum_{j} k_{i j}}=\left(\frac{1}{\tau_{i j}}\right)^{-1} .
$$

In Figure 11.12, we present reservoir residence times (leftmost column) and the rate constant matrix, the latter represented in the form of fractional response times $1 / k_{i j}$, which are more intuitive than fractional rate constants. In Figure 11.12, the row denotes the reservoir $(i)$ from which $\mathrm{C}$ is being removed and the column denotes the reservoir $(j)$ receiving $\mathrm{C}$ from $i$. Estimates of exogenic rate constants were guided by modern fluxes and reservoir sizes from Table 11.2 and an assumption of near steady state. For endogenic reservoirs, which are larger and may not be at steady state, our estimated rate constants are speculative. The modeler is encouraged to modify the endogenic rate constants to explore the behavior of the system. Empty boxes indicate the absence of flux. Boxes with a question mark indicate that there is a flux, but the magnitude of the flux and the rate constant are poorly known or change considerably with time. For example, degassing of the deep ocean to the atmosphere varies considerably between glacial-interglacial cycles. Transfer of $\mathrm{C}$ between the upper mantle and lower mantle is uncertain because it depends on the flux of mantle material between the two reservoirs, which is not known.

\subsubsection{Is Earth's Mantle Degassing or "Ingassing”?}

A key question is whether mantle degassing rates are balanced by recycling of $\mathrm{C}$ back into the mantle through subduction. The only direct way to answer this question is to compare 


\begin{tabular}{|c|c|c|c|c|c|c|c|c|c|c|c|}
\hline & \multicolumn{5}{|c|}{ Endogenic } & \multicolumn{4}{|c|}{ Exogenic } \\
\hline & & & Atm & Bio & \multicolumn{3}{|c|}{ ocean } & Oc Lith & Cont Lith & UM & LM \\
\hline \multirow{5}{*}{ 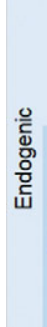 } & Atm & $-4 y$ & & $-10 y$ & $8-10 y$ & & & & & & \\
\hline & Bio & $-5-10 \mathrm{ky}$ & $-30 \mathrm{y}$ & & $\sim 3 \mathrm{ky}$ & & & & & & \\
\hline & Oc-S & $4-5 y$ & $-10 y$ & & & $-10 y$ & & & & & \\
\hline & Oc-D & $300-400 y$ & $?$ & & $\sim 300 y$ & & $40-50 \mathrm{ky}$ & & & & \\
\hline & Oc-rs & $3-4 \mathrm{ky}$ & & & & $-5 \mathrm{ky}$ & & $\begin{array}{c}-100-200 \mathrm{ky} \\
\left(\mathrm{CaCO}_{3}\right)\end{array}$ & $\begin{array}{r}\sim 15-30 \mathrm{ky} \\
\left(\mathrm{CaCO}_{3}\right)\end{array}$ & & \\
\hline \multirow{4}{*}{ 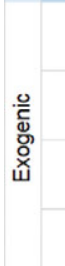 } & Oc Lith & $100-300 \mathrm{My}$ & $\begin{array}{l}-400 / f \mathrm{My} \\
\text { arc volc. }\end{array}$ & & & & & & $\begin{array}{l}\text {-400/f My } \\
\text { metasom. }\end{array}$ & $\begin{array}{c}-400 \mathrm{fm} \mathrm{My} \\
\text { mantle } \\
\text { wedge }\end{array}$ & $\begin{array}{c}\sim 400 / f \mathrm{My} \\
\text { deep } \\
\text { subduction }\end{array}$ \\
\hline & Cont Lith & $>1$ Gy & 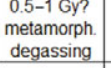 & & & & & & & & \\
\hline & UM & $\sim 1 \mathrm{~Gy}$ & $\begin{array}{c}-300 \mathrm{My} \\
\text { ridge }\end{array}$ & & & & & & & & ? \\
\hline & LM & $>1$ Gy & $\begin{array}{c}>1 \text { Gy plume } \\
\text { degassing }\end{array}$ & & & & & & & $?$ & \\
\hline
\end{tabular}

Figure 11.12 Matrix of kinetic rate constants between reservoirs, expressed as fractional response times or the inverse of the kinetic rate constant $\left(\tau_{i j}=k_{i j}{ }^{-1}\right)$. Each cell corresponds to the transfer of $\mathrm{C}$ from reservoir $i$ to $j$, where $i$ correspond to the row and $j$ corresponds to the column. Empty or gray cells indicate a lack of $\mathrm{C}$ transfer from $i$ to $j$. Cells with a question mark indicate that $\mathrm{C}$ transfer occurs, but the magnitude and rate constant are not known or vary significantly in time; these are left for the reader to vary in their own studies. Blue-shaded cells represent exogenic reservoirs. The blueoutlined group of cells represents ocean reservoirs, including reactive marine sediments. The leftmost column shows residence time $\tau_{i}$ of reservoir $i$. Reservoir symbols as follows: Atm $=$ atmosphere; Bio = terrestrial biosphere; Oc-S = surface ocean; Oc-D = intermediate and deep ocean; Oc-rs = reactive marine sediment; Oc Lith $=$ oceanic lithosphere, which includes oceanic crust and oceanic lithospheric mantle; Cont Lith $=$ continental lithosphere, which includes continental crust (sediments + basement) and CLM; UM = upper mantle $(<670 \mathrm{~km}) ; \mathrm{LM}=$ lower mantle $(>670 \mathrm{~km})$. Earth's core is excluded. " $\mathrm{f}$ " corresponds to the fraction of $\mathrm{C}$ from the subducting oceanic lithosphere that is lost to a particular reservoir.

mantle degassing fluxes to subduction fluxes, but these quantities are uncertain. A better approach is to explore possibilities through a forward box modeling approach as discussed in Section 11.6.1 and depicted in Figure 11.12. Rate constants can be allowed to vary with time as constrained by the physical evolution of Earth following simple, parameterized convection ${ }^{136}$ rather than full-scale coupling of thermodynamic and geodynamic models. For example, it is relatively straightforward to develop petrologically constrained scalings for mantle and crustal degassing as a function of mantle thermal state and convective vigor, with the goal of quantifying degassing at MORs, subducting slabs, arcs, and intraplate environments. Important quantities would be the kinetics of chemical weathering, but also where carbonates are deposited. In the extreme scenario in which all carbonates are deposited on continental shelves, which do not subduct, then there is little recycling of $\mathrm{C}$ back into the mantle. As far as we know, there is not yet any whole-Earth box model that 
Table 11.2 Fluxes of carbon

\begin{tabular}{lll}
\hline \hline Fluxes & Gton C/y & Refs. \\
\hline Exogenic & & \\
\hline Biosphere-atmosphere exchange & 60 & {$[12]$} \\
Surface ocean-atmosphere exchange & 70 & {$[12]$} \\
Surface-deep ocean exchange & 100 & {$[12]$} \\
Carbonate precipitation (silicate & $\mathbf{0 . 1 3 - 0 . 3 8}$ & {$[17]$} \\
weathering) & & \\
Organic C burial & $\mathbf{0 . 0 5 - 0 . 1 3}$ & This study, calculated from carbonate \\
& & precipitation with $f_{\text {org }}=0.2$ \\
Oceanic crust weathering & $\mathbf{0 . 0 3}$ & {$[107]$} \\
Weathering of carbonate and & $\mathbf{0 . 2 6 - 0 . 3 0}$ & \\
organic C (total) & & \\
Carbonate weathering & $0.22-0.25$ & This study, calculated from organic \\
& & C weathering (see below) \\
Organic C weathering & $0.043-0.050$ & {$[25]$} \\
Metamorphic degassing & $\mathbf{0 . 0 3 6 - 0 . 2 0 0}$ & {$[20]$} \\
Mantle degassing (total) & $\mathbf{0 . 0 8 5 - 0 . 3 0 0}$ & \\
MOR & $0.0158-0.0163$ & {$[19]$} \\
Ocean islands & $0.001-0.030$ & {$[18]$} \\
Arcs & $0.018-0.147$ & {$[21,78]$} \\
Modern continental rifts & $0.05-0.10$ & {$[79]$} \\
Subduction flux (sediments + & $0.024-0.048$ & \\
crust + lithospheric mantle) & & {$[22]$} \\
Miscellaneous & & \\
Mount Etna & & \\
Cretaceous continental arcs & 0.007 & {$[26]$} \\
Anthropogenic & 10 & \\
\hline & & \\
\hline
\end{tabular}

has incorporated the nature of how $\mathrm{C}$ is deposited (oceans versus continents). The important controls of where carbonates are deposited will be total area of shallow continental margins, the evolution of life, and the chemistry of the oceans. ${ }^{137,138}$ Variations of continental shelf area with time could be one of the most important factors controlling the rate at which $\mathrm{C}$ accumulates at the surface, as there are times in Earth's history when continents may have been wholly submerged, ${ }^{134,139,140}$ with most $\mathrm{C}$ being deposited in epicontinental seas, leaving little to be deposited in the deep sea for subduction.

In any case, we know that sedimentary rocks have accumulated on the continents over Earth's history. We also know that other incompatible elements, such as U, Th, and K, among others, have progressively migrated into the continental crust, leaving behind a depleted upper mantle. If $\mathrm{C}$ behaves incompatibly, then the continental crust and CLM $\mathrm{C}$ budget have likely grown with time as well. This growing continental reservoir of 
C serves as a capacitor, which can enhance outgassing rates by metamorphic or magmatically driven decarbonation of the lithosphere in continental $\operatorname{arcs}^{22}$ or continental rifts. ${ }^{79}$ If direct mantle degassing rates have not changed with time, total outgassing rates from the endogenic system should have increased with time. Alternatively, if mantle degassing rates are thought to have decreased significantly through time, lithospheric amplification could have partly compensated for this decline. Understanding how total outgassing rates from Earth's interior have changed through time will have profound implications for the evolution of other volatiles, whose chemistries may be linked to C. For example, an increasing outgassing flux of $\mathrm{C}$ would result in increased photosynthetic production of atmospheric oxygen. ${ }^{95}$

\subsubsection{What Drives Greenhouse and Icehouse Conditions?}

On 10-100-My timescales, Earth's climate fluctuates between greenhouse and icehouse states, the latter being characterized by permanent polar ice sheets and the former without permanent polar ice. For example, the late Jurassic to the early Cenozoic was characterized by greenhouse conditions, where temperatures were thought to be $>10^{\circ} \mathrm{C}$ higher than today and any ice sheets were thought to be ephemeral. This greenhouse interval was punctuated by a number of short-term $(<100-\mathrm{ky})$ excursions to even warmer conditions, often referred to as "hothouse" events. ${ }^{141}$

Earth began to cool around $50 \mathrm{Ma}$ in the mid-Cenozoic based on the seawater oxygen isotope record, with southern hemisphere glaciation (Antarctica) beginning 35 Ma, followed by the development of the northern hemisphere ice sheet $\sim 5 \mathrm{Ma}^{4,36}$ Earth in the last several million years has been characterized by bipolar glaciation, and because of the albedo effect of ice, subtle variations in solar insolation driven by orbital dynamics can drive short-term cycles (10-100 ky) of ice sheet growth and retreat. Thus, superimposed on the late Cenozoic icehouse baseline are geologically rapid periodic fluctuations of temperature, ice volume, and eustatic sea level tuned to orbital dynamics. During greenhouse intervals, apparent changes in relative sea level (e.g. sequence boundaries ${ }^{142,143}$ ) recorded during greenhouse conditions most likely have origins that are different from glacioeustasy, such as external changes in sediment supply. While rapid fluctuations in sea level are a defining characteristic of an icehouse world, short-lived hothouse excursions - a characteristic feature of greenhouse intervals - appear to be absent from icehouse worlds.

Two questions follow. First, what controls baseline climate? Second, what conditions allow for and trigger short-term excursions to extreme warm and cold climates? In general, baseline climate on $>10$-My timescales is ultimately controlled by the amount of greenhouse gases in the atmosphere, namely $\mathrm{CO}_{2}$ for most of Earth's history. Orbital dynamics are too rapid, while changes in the sun's luminosity only explain changes over Gy. Understanding long-term baselines comes down to understanding what controls the steady state. The combination of volcanic/metamorphic forcings (input) and the efficiency of the silicate weathering feedback defines a given steady state, and it is the variations in these two quantities that we seek to understand. ${ }^{30}$ 


\subsubsection{Greenhouse Intervals}

A widely held view is that the late Mesozoic and early Cenozoic greenhouse conditions were driven by a 1.5- to 2-fold increase in MOR spreading rates, leading to an increase in $\mathrm{CO}_{2}$ output from the mantle. ${ }^{3,80,81}$ The contribution from oceanic spreading may have been enhanced by a greater emplacement frequency of large igneous provinces. ${ }^{80}$ Mid-Cenozoic cooling toward icehouse conditions is widely thought to have been driven by an increase in the efficiency of the silicate weathering feedback through the collision of India with Eurasia and the uplift of the Himalayas and Tibet. ${ }^{124,125}$

There are, however, reasons to explore other hypotheses. One question is whether enhanced MOR spreading was able to sustain a Cretaceous $\mathrm{pCO}_{2}$ that was 5-10 times higher than present (Figure 11.1b). If $\mathrm{CO}_{2}$ concentrations in Mesozoic MORBs were similar to today's, the increase in $\mathrm{CO}_{2}$ production rates would scale roughly linearly with the increase in spreading rate. Assuming a linear negative feedback, the enhanced spreading rates would lead to only a 1.5 - to 2 -fold increase in atmospheric $\mathrm{CO}_{2}$, or the global silicate weathering feedback would have to have been less efficient. The latter seems unlikely because weathering kinetics should increase in the hotter and wetter conditions of greenhouse climates. Furthermore, the late Mesozoic to early Cenozoic was characterized by significant orogenic activity in the form of Andean-style continental arcs. Thus, weathering feedback strength during the late Mesozoic greenhouse should have been high, requiring even higher inputs of $\mathrm{CO}_{2}$ to sustain the elevated $\mathrm{pCO}_{2}$.

Recently, it has been suggested that length of continental arcs during the Cretaceous was 1.5-2 times longer than that of the mid-Cenozoic. ${ }^{22}$ Due to the large amounts of carbonate stored in the continental crust, continental arcs may degas more $\mathrm{CO}_{2}$ through metamorphic and magmatically induced decarbonation of crustal carbonate; thus, a global chain of continental arcs might amplify global $\mathrm{CO}_{2}$ outgassing. ${ }^{22,86,144}$ Long-term fluctuations in the length of continental arcs, driven by the assembly and dispersal of continents, have been suggested to drive greenhouseicehouse oscillations based on studies of the detrital zircon record and arc length through time. ${ }^{88,145}$ Lee et al. ${ }^{22}$ showed that the long Cretaceous continental arcs may have supported a flux of $0.09-0.13$ Gton $\mathrm{C} / \mathrm{y}$, more than twice that of global magmatic arcs today (Figure 11.8b). This hypothesis has been contested by Pall et al., ${ }^{146}$ who argue for a weak correlation between carbonate-intersecting continental arcs and high $\mathrm{pCO}_{2}$. However, this study did not incorporate the Precambrian distribution of carbonates or uncertainties in the paleo- $\mathrm{pCO}_{2}$ record. In any case, other factors to be considered are the competing effects of enhanced erosion and weathering during continental arc magmatism ${ }^{147,148}$ and the slab contribution to $\mathrm{CO}_{2}$ fluxing through arcs, the latter requiring an understanding of slab composition, slab thermal state, and $\mathrm{CO}_{2}$ solubility in fluids and melts, among other factors. In any case, faster spreading, faster subduction, more plumes, and a transition to continental arcs over island arcs may operate together, ${ }^{149}$ making it difficult to ascribe greenhouse intervals to a single process. 


\subsubsection{Icehouse Drivers}

Are long-lived icehouses driven by enhanced silicate weathering feedbacks or decreased outgassing from Earth's interior? The Cretaceous greenhouse and mid-Cenozoic to present icehouse represent an ideal case study. It is widely thought that the Himalayan orogeny played a strong role in Cenozoic cooling beginning 50 Ma by enhancing the silicate weathering feedback through enhanced erosion rates. ${ }^{125}$ However, the rise in ${ }^{87} \mathrm{Sr} /{ }^{86} \mathrm{Sr}$ often touted as an indicator of terrestrial weathering occurs $\sim 38 \mathrm{Ma}$, well after cooling initiated. ${ }^{150,151}$ Furthermore, radiogenic isotopes do not necessarily correlate with silicate weathering fluxes because source age and composition can be just as important. ${ }^{152}$ For example, local weathering of ultramafics or black shales has an outsized influence on seawater ${ }^{187} \mathrm{Os} /{ }^{188} \mathrm{Os} .{ }^{153,154}$ Similarly, weathering of carbonates or the very ancient basement influences ${ }^{87} \mathrm{Sr} /{ }^{86} \mathrm{Sr} .{ }^{152}$

These complications in interpreting seawater $\mathrm{Sr}$ isotopes raise a number of important questions. Is the Himalayan orogeny, in a regional sense, a net producer or consumer of $\mathrm{CO}_{2} ?^{94,96,97}$ This, combined with the possibility that regional metamorphism causes metamorphic decarbonation of crustal carbonates, should encourage vigorous discussion on the role of the Himalayan orogeny on global cooling. Recent studies have suggested that the closing of the Tethys ocean, which culminated in a transcontinental orogenic belt, of which the Himalayas are but one segment, involved the obduction of numerous island arc terranes and ophiolites, increasing global silicate weathering efficiency. ${ }^{155} \mathrm{In}$ an alternative scenario, Kent et al. ${ }^{156}$ suggested that the $\sim 65$-Ma Deccan flood basalts in India may have increased global weathering efficiency as India migrated north into wet equatorial latitudes in the Cenozoic.

There is also the possibility that cool climates simply represent a decline in magmatic outgassing. ${ }^{157}$ Evidence from detrital zircons and arc reconstructions have been used to suggest that long icehouse intervals coincide with periods of reduced continental arc activity, just as greenhouses have been suggested to correlate with enhanced continental arc activity. ${ }^{22,87,88,145}$ The rise and fall of continental arcs offer an intriguing process for modulating the exogenic $\mathrm{C}$ system. When continental arcs are magmatically active, they are likely to be net producers of $\mathrm{CO}_{2}$, but after magmatism wanes, the remnant topography transforms continental arcs into regional sinks of $\mathrm{CO}_{2}$, resulting in a global increase in the efficiency of silicate weathering. ${ }^{147,148}$ In such a scenario, magmatic outgassing drives greenhouse intervals, which are followed by icehouse intervals when the same orogens die magmatically but continue to weather (Figure 11.13).

Ice sheets may also influence the long-term climate. Growth of ice sheets increases albedo, which cools the climate and encourages additional ice sheet growth. Could ice sheet expansion have further facilitated Cenozoic cooling by enhancing the silicate weathering associated with glacial erosion? This is a tantalizing thought as the Antarctic ice sheet is situated on the ancient Archean basement, raising the question of whether the onset of Antarctic glaciation at $\sim 35$ Ma may have played a role in the rise of seawater $\mathrm{Sr}$ isotopes at about the same time. On the other hand, glacial weathering might even result in the net production of $\mathrm{CO}_{2}$ through the oxidation of sulfides, which in turn drives carbonate 
(a)

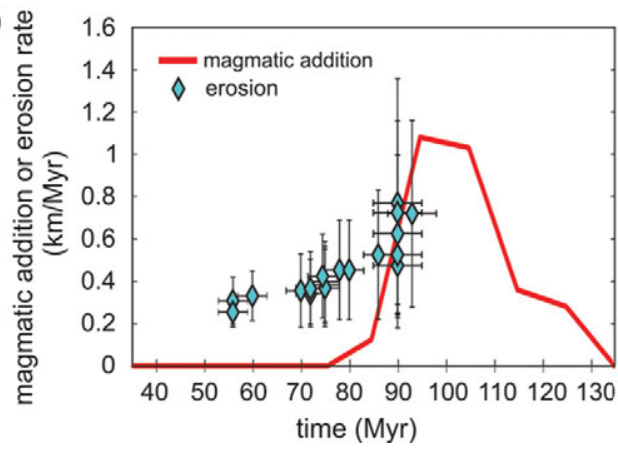

(b)

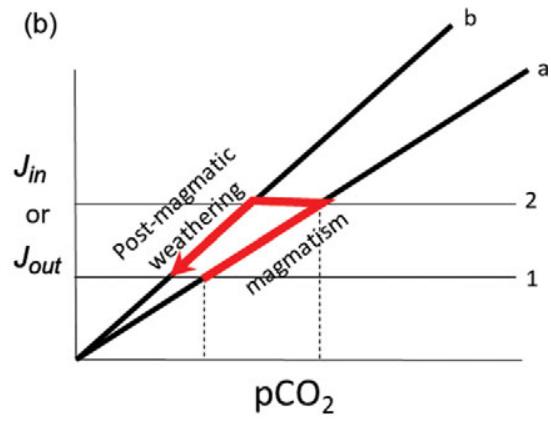

Figure 11.13 (a) Case study of a magmatic orogen: Cretaceous Peninsular Ranges batholith in southern California, USA. ${ }^{147}$ Red line shows the observed magmatic production rate and symbols with error bars represent inferred erosion rates. The orogen is characterized by both magmatism (and $\mathrm{CO}_{2}$ degassing) and erosion, but they are not in phase. After magmatism ends, remnant topography allows for continued erosion and regional drawdown of $\mathrm{CO}_{2}$ unsupported by magmatic degassing. (b) Global effect of magmatic orogen on steady-state $\mathrm{pCO}_{2}$. Details of the plot are identical to those of Figure 11.5. Magmatic orogeny increases $\mathrm{CO}_{2}$ outgassing, so $\mathrm{pCO}_{2}$ increases from states 1 to 2 . Uplift during magmatism enhances erosion, increasing the sensitivity of the global weathering feedback (states a to b), which buffers the rise of $\mathrm{pCO}_{2}$. After magmatism ends, physical and chemical weathering persist, driving $\mathrm{pCO}_{2}$ to low levels. Magmatic orogens can potentially drive greenhouses, but are followed by global cooling due to protracted weathering.

dissolution; because the resulting acidity is driven by sulfide oxidation rather than carbonation itself, this results in a net release of $\mathrm{CO}_{2}$, counteracting the effects of glacial weathering and the ice-albedo positive feedback. ${ }^{158,159}$

\subsubsection{Climatic Excursions and Runaways}

\subsubsection{Hothouses}

The Mesozoic-early Cenozoic greenhouse was punctuated by short-lived hothouse excursions, including the three oceanic anoxia events in the Cretaceous (OAE-1, -2, and -3) and the late PETM and surrounding hothouse excursions ("hyperthermals"). ${ }^{36,141,160,161}$ Many of these excursions have in common an increase in temperature and $\mathrm{pCO}_{2}$, but different triggers. The PETM is characterized by a negative $\mathrm{C}$ isotope excursion, leading to suggestion that methane hydrates in the marine system were destabilized and released into the atmosphere. ${ }^{35}$ Other mechanisms, such as destabilization of peat, opening of the North Atlantic Ocean, and even cometary impact, ${ }^{162-164}$ have also been suggested for the PETM. Emplacement of the Caribbean flood basalt is thought to have driven Cretaceous OAE-2 at the Cenomanian-Turonian boundary, ${ }^{165,166}$ with volcanic release of $\mathrm{CO}_{2}$ leading to global warming, which in turn decreased the solubility of $\mathrm{O}_{2}$ in the ocean and setting conditions to be favorable for organic $\mathrm{C}$ preservation. ${ }^{166}$ 
Hothouse excursions clearly have different triggers, but occur only during long-lived greenhouse baselines, not during icehouse baselines. Greenhouse baselines may be close to the threshold for hothouse excursions, such that any number of stochastic events could trigger an excursion if the system is close to threshold. The fact that hothouses return rapidly to baseline is further evidence that short-lived episodic events are responsible for triggering hothouses. Flood basalts, methane hydrate destabilization, and cometary impacts, among others, are all singular events that cannot sustain a long-term transition to a new steady state (unless the system is characterized by multiple steady states). These hothouse excursions all return to baseline because of the buffering effects of the silicate weathering feedback.

In some cases, excursions run away to a fundamentally different state. Unlike Earth, Venus is in a permanent hothouse. In part, this is due to continuous accumulation of $\mathrm{CO}_{2}$ or other greenhouse gases from the Venusian interior, enhanced by the fact that Venus has not had an efficient mechanism (e.g. weathering) for geologically sequestering C. The Venusian crust appears to be continually resurfaced, so the lack of weathering is not due to lack of a continuous supply of fresh material. Rather, surface conditions are so hot that water remains as a vapor, preventing the precipitation of liquid water to serve as a medium to dissolve rocks. ${ }^{34}$ An explanation for Venus's perpetual hothouse is that Venus crossed a threshold of atmospheric $\mathrm{CO}_{2}$, which resulted in enough warming to vaporize significant amounts of water. Water itself is an effective greenhouse gas, which further warms the atmosphere, in turn evaporating more water, until the system runs away to a new hothouse steady state. The greenhouse effect of water vapor on Earth is limited by the fact that water condenses and rains out, preventing runaway. Venus may have been more prone to cross this threshold because it lies closer to the sun.

\subsubsection{Snowballs}

During the Neoproterozoic and the early Paleoproterozoic, our planet appears to have almost completely frozen over ("Snowball”) based on the presence of low-latitude glacial sediments. In the Neoproterozoic, there were two or three Snowballs, which may have lasted 10-50 My. ${ }^{7,8}$ During Neoproterozoic Snowball times, most of the continents were situated near the equator, which would have resulted in a strong ice-albedo feedback once ice sheets began to grow on these equatorial continents, ultimately leading to runaway glaciation.

It is generally agreed that the long-term baseline $\mathrm{pCO}_{2}$ during the Neoproterozoic was low, but why this was the case is debated. One hypothesis is that continents were preferentially at low latitudes and would thus have been characterized by higher silicate weathering kinetics. A recent variant of this hypothesis invokes emplacement of the Franklin large igneous province, which increased global weatherability due to the increased surface area of easily weathered basalt. ${ }^{167}$ Other hypotheses argue that continents were in a dispersed state during Neoproterozoic times, resulting in increased continental margins, which in turn accelerated biological productivity and enhanced the efficiency of $\mathrm{C}$ sequestration through organic $\mathrm{C}$ burial. ${ }^{7,8}$ Highly positive seawater $\mathrm{C}$ isotopes predating 
the onset of the Snowball intervals are consistent with an unusually high fraction of organic C burial before each Snowball. Others have suggested that there was a paucity of continental arcs during the Neoproterozic, resulting in a decrease in global magmatic outputs. ${ }^{87,88,145}$ Importantly, none of these scenarios is unique to the Neoproterozoic, which suggests that without the unique backdrop of low-latitude continents and low magmatic outputs, the conditions needed to cross the threshold would not otherwise have been met.

\subsection{Summary and Further Research Directions}

This chapter discussed the $\mathrm{C}$ cycling and long-term climate from a whole-Earth systems perspective. A conceptual framework for modeling $\mathrm{C}$ cycling between each reservoir was presented, along with a summary of the inventories of $\mathrm{C}$ in Earth's major reservoirs and the fluxes of $\mathrm{C}$ between them. Long-term climate ( $>1 \mathrm{My}$ ) is controlled by the amount of $\mathrm{C}$ in the exogenic system (atmosphere, ocean, and biosphere), which itself is controlled by exchange between the endogenic (crust and mantle) and exogenic systems. Total exogenic $\mathrm{C}$ is controlled by outgassing from Earth's interior via volcanism/metamorphism and sequestration of carbonate and organic $\mathrm{C}$ via silicate weathering and photosynthesis. The response time for silicate weathering is on the order of $100 \mathrm{ky}$, such that the amount of $\mathrm{C}$ in the exogenic system, and by implication climate, is at steady state on timescales longer than $1 \mathrm{My}$ and endogenic inputs and exogenic outputs are balanced. Any long-term climate variability must reflect changing steady states, defined by temporal changes in the magnitude of volcanic and metamorphic inputs or in the efficiency (e.g. strength of weathering kinetics) of silicate weathering feedbacks, which draw down $\mathrm{CO}_{2}$ by precipitating carbonate. Silicate weathering serves as a negative feedback because $\mathrm{CO}_{2}$ drawdown increases with increasing $\mathrm{pCO}_{2}$ through a complex series of transfer functions, in which increasing $\mathrm{pCO}_{2}$ increases acidity and surface temperature, the latter of which increases precipitation and runoff, all of which enhance dissolution rates. Although tectonics and mantle dynamics drive endogenic outgassing, these endogenic processes can also enhance silicate weathering through tectonically driven erosion.

Long-term greenhouse intervals are likely driven by enhanced MOR spreading or the length of continental rifts and carbonate-intersecting continental arcs. Long-term icehouses have been widely thought to be driven by enhanced global weathering kinetics through an increase in orogenic activity, but decreased endogenic outgassing may be more important. Magmatic orogens may drive greenhouse intervals, but after magmatism ends, erosion and weathering of remnant topography increases global weathering kinetics, causing colder climates to immediately follow. The continental crust and CLM represent large repositories of $\mathrm{C}$ in the form of sediments, metamorphic $\mathrm{C}$ in the crust, and metasomatized domains in the lithospheric mantle. This continental $\mathrm{C}$ can be periodically tapped during rifting and continental arc magmatism, leading to greenhouse states. Below, we list several questions to guide future research. 
What controls baseline $\mathbf{C}$ in the exogenic system and hence climate? Specifically, what is more effective in changing baseline $\mathrm{C}$ : changes in source or in the efficiency of the sink ${ }^{168}$ What are the relative roles of MORs, plumes, continental arcs, continental rifts, and orogens in controlling $\mathrm{C}$ inputs? How do global weathering kinetics change with time or with changes in the nature of Earth's surface? What is the functional form of the silicate weathering feedback? Are orogens net regional sources or sinks of $\mathrm{C}$ ?

How has the lithospheric (crust + lithospheric mantle) reservoir of $\mathrm{C}$ changed through time? The answer to this question is key to quantifying how mantle degassing and metamorphic fluxes change with time. Progress may come from characterizing average amounts of carbonate and graphite in igneous and metamorphic basement rocks (see Ref. 169). It will also be important to build a more quantitative budget of carbonate- and organic C-bearing sediments on the continents (see Ref. 170).

How has the spatial and temporal distribution of $\mathrm{C}$ deposition changed through time? Specifically, how has $\mathrm{C}$ deposition been partitioned between the shallow and deep sea through time? Also of interest is whether organic $\mathrm{C}$ and carbonate remain coupled during sedimentary deposition; if not, the bulk redox state of total $\mathrm{C}$ will vary regionally, with implications for the redox state of subducted materials.

How did early Earth volatile cycles operate? During much of Earth's history, atmospheric oxygen levels were low. Questions thus arise as to whether $\mathrm{CO}_{2}$ or some other carbon species, such as methane, was the dominant greenhouse gas during those times. Were Archean atmospheric $\mathrm{CO}_{2}$ contents much higher than today, as seems to be required by a lower solar luminosity (a faint young sun) ${ }^{1}$ If other greenhouse gases were more important in the Archean, how would weathering feedbacks have behaved?

How have changes in the nature of the $C$ cycle influenced the cycling of other elements on Earth? The dominant form of di-oxygen $\left(\mathrm{O}_{2}\right)$ production on Earth is through photosynthetic reduction of $\mathrm{CO}_{2}$ to organic $\mathrm{C}$. The evolution of atmospheric $\mathrm{O}_{2}$ is thus controlled by the $\mathrm{C}$ cycle. Oxygen availability in turn influences the geochemical behaviors of redox-sensitive elements, such as $\mathrm{S}, \mathrm{N}$, and metals, as well as elements like $\mathrm{P}$ that complex with or absorb onto metals of a certain oxidation state.

We conclude our review with the caveat that what we have discussed here is strongly biased by our experiences on Earth. Nevertheless, the concepts presented here should be transportable to understanding element cycles and climates on other planets in our solar system or beyond.

\section{Acknowledgments}

This work was supported by the US NSF Frontiers of Earth Systems Dynamics grant (OCE-1338842) and a NASA grant 80NSSC18K0828. We thank the organizers Craig Manning and Isabelle Daniel of the 2018 Deep Carbon Science Gordon Research Conference in Rhode Island for providing inspiration. We also thank L. Carter, D. Catling, M. Edmonds, J. Eguchi, D. Grewal, M. Kastner, A. Lenardic, T. Lyons, D. Müller, 
T. Plank, K. Siebach, J. Tucker, A. J. West, and L. Yeung for various insights. We thank Jeremy Caves for his insightful review.

\section{References}

1. Sagan, C. \& Mullen, G. Earth and Mars: evolution of atmospheres and surface temperatures. Science 177, 52-56 (1972).

2. Walker, J. C. G., Hays, P. B. \& Kasting, J. F. A negative feedback mechanism for the long-term stabilization of Earth's surface temperature. J. Geophys. Res. 86, 9776-9782 (1981).

3. Berner, R. A. The Phanerozoic Carbon Cycle: $\mathrm{CO}_{2}$ and $\mathrm{O}_{2}$ (Oxford University Press, 2004).

4. Zachos, J. C., Dickens, G. R. \& Zeebe, R. E. An early Cenozoic perspective on greenhouse warming and carbon-cycle dynamics. Nature 451, 279-283 (2008).

5. Hays, J. D., Imbrie, J. \& Shackleton, N. J. Pacemaker of the ice ages. Science 194, 1121-1132 (1976).

6. Huybers, P. \& Wunsch, C. Obliquity pacing of the late Pleistocene glacial terminations. Nature 434, 491-494 (2005).

7. Hoffman, P. F. \& Schrag, D. P. The snowball Earth hypothesis: testing the limits of global change. Terra Nova 14, 129-155 (2002).

8. Hoffman, P. F., Kaufman, A. J., Halverson, G. P. \& Schrag, D. P. A Neoproterozoic Snowball Earth. Science 281, 1342-1346 (1998).

9. Berner, R. A. A model for atmospheric $\mathrm{CO}_{2}$ over Phanerozoic time. Am. J. Sci. 291, 339-376 (1991).

10. Royer, D. L., Berner, R. A., Montanez, I. P., Tabor, N. J. \& Beerling, D. J. $\mathrm{CO}_{2}$ as a primary driver of Phanerozoic climate. Geol. Soc. Am. Today 14, 4-10 (2004).

11. Sundquist, E. T. \& Visser, K. The geologic history of the carbon cycle. Treat. Geochem. 8, 425-472 (2011).

12. Sundquist, E. T. The global carbon dioxide budget. Science 259, 934-941 (1993).

13. Sundquist, E. T. Geological perspectives on carbon dioxide and the carbon cycle. In: The Carbon cycle and Atmospheric $\mathrm{CO}_{2}$ : Natural Variations Archean to Present, Vol. 32 (eds. E. T. Sundquist \& W. S. Broecker), 5-60 (American Geophysical Union, 1985).

14. Sarmiento, J. L. \& Gruber, N. Sinks for anthropogenic carbon. Phys. Today 5, 30-36 (2002).

15. Doval, M. D. \& Hansell, D. A. Organic carbon and apparent oxygen utilization in the western South Pacific and the central Indian Oceans. Marine Chem. 68, 249-264 (2000).

16. Hansell, D. A. \& Carlson, C. A. Deep-ocean gradients in the concentration of dissolved organic carbon. Nature 395, 263-266 (1998).

17. Gaillardet, J., Dupre, B., Louvat, P. \& Allegre, C. J. Global silicate weathering and $\mathrm{CO}_{2}$ consumption rates deduced from the chemistry of large rivers. Chem. Geol. 159, 3-30 (1999).

18. Dasgupta, R. \& Hirschmann, M. M. The deep carbon cycle and melting in Earth's interior. Earth Planet. Sci. Lett. 298, 1-13 (2010).

19. Tucker, J. M., Mukhopadhyay, S. \& Gonnermann, H. M. Reconstructing mantle carbon and noble gas contents from degassed mid-ocean ridge basalts. Earth Planet. Sci. Lett. 496, 108-119 (2018). 
20. Kerrick, D. M. \& Caldeira, K. Metamorphic $\mathrm{CO}_{2}$ degassing from orogenic belts. Chem. Geol. 145, 213-232 (1998).

21. Burton, M. R., Sawyer, G. M. \& Granieri, D. Deep carbon emissions from volcanoes. Rev. Mineral. Geochem. 75, 323-354 (2013).

22. Lee, C.-T. A. et al. Continental arc-island arc fluctuations, growth of crustal carbonates and long-term climate change. Geosphere 9, 21-36 (2013).

23. Lee, C.-T. A. \& Lackey, J. S. Global continental arc flare-ups and their relation to long-term greenhouse conditions. Elements 11, 125-130 (2015).

24. Allard, P. et al. Eruptive and diffuse emissions of $\mathrm{CO}_{2}$ from Mount Etna. Nature 351, 387-391 (1991).

25. Petsch, S. T. Weathering of organic carbon. Treat. Geochem. 12, 217-238 (2014).

26. Friedlingstein, P. et al. Update on $\mathrm{CO}_{2}$ emissions. Nat. Geosci. 3, 811-812 (2010).

27. Berner, R. A. \& Caldeira, K. The need for mass balance and feedback in the geochemical carbon cycle. Geology 25, 955-956 (1997).

28. Broecker, W. S. \& Sanyal, A. Does atmospheric $\mathrm{CO}_{2}$ police the rate of chemical weathering. Global Biogeochem. Cycles 12, 403-408 (1998).

29. Lasaga, A. C. Kinetic Theory in the Earth Sciences (Princeton University Press, 1998).

30. Caves, J. K., Jost, A. B., Lau, K. V. \& Maher, K. Cenozoic carbon cycle imbalances and a variable silicate weathering feedback. Earth Planet. Sci. Lett. 450, 152-163 (2016).

31. Kump, L. R. \& Arthur, M. A. Global chemical erosion during the Cenozoic: weatherability balances the budgets. In: Tectonic Uplift and Climate Change (ed. W. F. Ruddiman), 399-426 (Plenum Press, 1997).

32. Zeebe, R. E. \& Caldeira, K. Close mass balance of long-term carbon fluxes from icecore $\mathrm{CO}_{2}$ and ocean chemistry records. Nat. Geosci. 1, 312-315 (2008).

33. Lodders, K. \& Fegley, J. B. The Planetary Scientist's Companion (Oxford University Press, 1998).

34. Ingersoll, A. P. Planetary Climates (Princeton University Press, 2013).

35. Dickens, G. R., O’Neil, J. R., Rea, D. K. \& Owen, R. M. Dissociation of oceanic methane hydrate as a cause of the carbon isotope excursion at the end of the Paleocene. Paleoceanography 10, 965-971 (1995).

36. Zachos, J., Pagani, M., Sloan, L., Thomas, E. \& Billups, K. Trends, rhythms, and aberrations in global climate 65 Ma to present. Science 292, 686-693 (2001).

37. Saal, A. E., Hauri, E. H., Langmuir, C. H. \& Perfit, M. R. Vapour undersaturation in primitive mid-ocean-ridge basalt and the volatile content of Earth's upper mantle. Nature 419, 451-455 (2002).

38. Hirschmann, M. M. \& Dasgupta, R. The H/C ratios of Earth's near-surface and deep reservoirs, and consequences for deep Earth volatile cycles. Chem. Geol. 262, 4-16 (2009).

39. Marty, B. \& Jambon, A. $\mathrm{C} /{ }^{3} \mathrm{He}$ in volatile fluxes from the solid Earth: implications for carbon geodynamics. Earth Planet. Sci. Lett. 83, 16-26 (1987).

40. Michael, P. J. \& Graham, D. W. The behavior and concentration of $\mathrm{CO}_{2}$ in the suboceanic mantle: inferences from undegassed ocean ridge and ocean island basalts. Lithos 236-237, 338-351 (2015).

41. Rosenthal, A., Hauri, E. H. \& Hirschmann, M. M. Experimental determination of C, $\mathrm{F}$, and $\mathrm{H}$ partitioning between mantle minerals and carbonated basalt, $\mathrm{CO}_{2} / \mathrm{Ba}$ and $\mathrm{CO}_{2} / \mathrm{Nb}$ systematics of partial melting, and the $\mathrm{CO}_{2}$ contents of basaltic source regions. Earth Planet. Sci. Lett. 412, 77-87 (2015). 
42. Anderson, D. L. Theory of the Earth (Blackwell, 1989).

43. Hofmann, A. W. Chemical differentiation of the Earth: the relationship between mantle, continental crust, and oceanic crust. Earth Planet. Sci. Lett. 90, 297-314 (1988).

44. Zindler, A. \& Hart, S. Chemical geodynamics. Annu. Rev. Earth Planet. Sci. 14, 493-571 (1986).

45. Chi, H., Dasgupta, R., Duncan, M. S. \& Shimizu, N. Partitioning of carbon between Fe-rich alloy melt and silicate melt in a magma ocean - implications for the abundance and origin of volatiles in Earth, Mars and the Moon. Geochim. Cosmochim. Acta 139, 447-471 (2014).

46. Workman, R. K. \& Hart, S. R. Major and trace element composition of the depleted MORB mantle (DMM). Earth Planet. Sci. Lett. 231, 53-72 (2005).

47. McDonough, W. F. \& Sun, S.-S. The composition of the Earth. Chem. Geol. 120, 223-253 (1995).

48. Elliott, T., Plank, T., Zindler, A., White, W. \& Bourdon, B. Element transport from slab to volcanic front at the Mariana arc. J. Geophys. Res. 102, 14991-15019 (1997).

49. Kelemen, P. B. \& Manning, C. E. Reevaluating carbon fluxes in subduction zones, what goes down, mostly comes up. Proc. Natl Acad. Sci. 112, E3997-E4006 (2015).

50. Duncan, M. S. \& Dasgupta, R. Rise of Earth's atmospheric oxygen controlled by efficient subduction of organic carbon Nat. Geosci. 10, 387-392 (2017).

51. Dasgupta, R. Ingassing, storage, and outgassing of terrestrial carbon through geologic time. Rev. Mineral. Geochem. 75, 183-229 (2013).

52. Hirschmann, M. M. Comparative deep Earth volatile cycles: the case for $\mathrm{C}$ recycling from exosphere/mantle fractionation of major $\left(\mathrm{H}_{2} \mathrm{O}, \mathrm{C}, \mathrm{N}\right)$ volatiles and from $\mathrm{H}_{2} \mathrm{O} / \mathrm{Ce}, \mathrm{CO}_{2} / \mathrm{Ba}$, and $\mathrm{CO}_{2} / \mathrm{Nb}$ exosphere ratios. Earth Planet. Sci. Lett. 502, 262-273 (2018).

53. Hofmann, A. W. \& White, W. M. Mantle plumes from ancient oceanic crust. Earth Planet. Sci. Lett. 57, 421-436 (1982).

54. Garapić, G., Mallik, A., Dasgupta, R. \& Jackson, M. G. Oceanic lavas sampling the high- ${ }^{3} \mathrm{He} /{ }^{4} \mathrm{He}$ mantle reservoir: primitive, depleted, or re-enriched? Am. Mineral. 100, 2066-2081 (2015).

55. Wilkinson, B. H. \& Walker, J. C. G. Phanerozoic cycling of sedimentary carbonate. Am. J. Sci. 289, 525-548 (1989).

56. Wilkinson, B. H. \& Algeo, T. J. Sedimentary carbonate record of calciummagnesium cycling. Am. J. Sci. 289, 1158-1194 (1989).

57. Ronov, A. B. Evolution of rock composition and geochemical processes in the sedimentary shell of the Earth. Sedimentology 19, 157-172 (1972).

58. Wedepohl, K. H. The composition of the continental crust. Geochim. Cosmochim. Acta 59, 1217-1232 (1995).

59. Gao, S. et al. Chemical composition of the continental crust as revealed by studies in East China. Geochim. Cosmochim. Acta 62, 1959-1975 (1998).

60. Jordan, T. H. Composition and development of the continental tectosphere. Nature 274, 544-548 (1978).

61. Lee, C.-T. A., Luffi, P. \& Chin, E. J. Building and destroying continental mantle. Annu. Rev. Earth Planet. Sci. 39, 59-90 (2011).

62. Griffin, W. L., O'Reilly, S. Y. \& Ryan, C. G. The composition and origin of subcontinental lithospheric mantle. In: Mantle Petrology: Field Observations and High Pressure Experimentation: A Tribute to R. (Joe) Boyd, eds. Yingwei Fei, Constance M. Bertka \& Bjorn O. Mysen, Vol. 6, 13-45 (Geochemical Society, 1999). 
63. Gung, Y., Panning, M. \& Romanowicz, B. Global anisotropy and the thickness of continents. Nature 422, 707-711 (2003).

64. Pearson, D. G. et al. Re-Os, Sm-Nd, and Rb-Sr isotope evidence for thick Archaean lithospheric mantle beneath the Siberian craton modified by multistage metasomatism. Geochim. Cosmochim. Acta 59, 959-977 (1995).

65. Pearson, D. G., Carlson, R. W., Shirey, S. B., Boyd, F. R. \& Nixon, P. H. Stabilisation of Archaean lithospheric mantle: a Re-Os isotope study of peridotite xenoliths from the Kaapvaal craton. Earth Planet. Sci. Lett. 134, 341-357 (1995).

66. Carlson, R. W., Pearson, D. G. \& James, D. E. Physical, chemical, and chronological characteristics of continental mantle. Rev. Geophys. 43, RG1001 (2005).

67. Walker, R. J., Carlson, R. W., Shirey, S. B. \& Boyd, F. R. Os, Sr, Nd, and Pb isotope systematics of southern African peridotite xenoliths: implications for the chemical evolution of subcontinental mantle. Geochim. Cosmochim. Acta 53, 1583-1595 (1989).

68. Foley, S. F. Rejuvenation and erosion of the cratonic lithosphere. Nat. Geosci. 1, 503-510 (2008).

69. Li, Z.-X. A., Lee, C.-T. A., Peslier, A. H., Lenardic, A. \& Mackwell, S. J. Water contents in mantle xenoliths from the Colorado Plateau and vicinity: implications for the rheology and hydration-induced thinning of continental lithosphere. J. Geophys. Res. 113, B09210 (2008).

70. Ionov, D. A., Doucet, L. S. \& Ashchepkov, I. V. Composition of the lithospheric mantle in the Siberian Craton: new constraints from fresh peridotites in the Udachnaya-East kimberlite. J. Petrol. 51, 2177-2210 (2010).

71. Ionov, D. A., Chanefo, I. \& Bodinier, J.-L. Origin of Fe-rich lherzolites and wehrlites from Tok, SE Siberia by reactive melt percolation in refractory mantle peridotites. Contrib. Mineral. Petrol. 150, 335-353 (2005).

72. Ionov, D. A., Bodinier, J.-L., Mukasa, S. B. \& Zanetti, A. Mechanisms and sources of mantle metasomatism: major and trace element compositions of peridotite xenoliths from Spitsbergen in the context of numerical modelling. J. Petrol. 43, 2219-2259 (2002).

73. Zheng, J. P. et al. Refertilization-driven destabilization of subcontinental mantle and the importance of initial lithospheric thickness for the fate of continents. Earth Planet. Sci. Lett. 409, 225-231 (2015).

74. Saha, S., Dasgupta, R. \& Tsuno, K. High pressure phase relations of a depleted peridotite fluxed by $\mathrm{CO}_{2}-\mathrm{H}_{2} \mathrm{O}$-bearing siliceous melts and the origin of midlithospheric discontinuity. Geochem. Geophys. Geosyst. 19, 595-620 (2018).

75. Dasgupta, R. Volatile-bearing partial melts beneath oceans and continents - where, how much, and of what compositions? Am. J. Sci. 318, 141-165 (2018).

76. Duncan, M. S. \& Dasgupta, R. Pressure and temperature dependence of $\mathrm{CO}_{2}$ solubility in hydrous rhyolitic melt - implications for carbon transfer to mantle source of volcanic arcs via partial melting of subducting crustal lithologies. Contrib. Mineral. Petrol. 169, 54 (2015).

77. Dickens, G. R. Rethinking the global carbon cycle with a large, dynamic and microbially mediated gas hydrate capacitor. Earth Planet. Sci. Lett. 213, 169-183 (2003).

78. Marty, B. \& Tolstikhin, I. N. $\mathrm{CO}_{2}$ fluxes from mid-ocean ridges, arcs and plumes. Chem. Geol. 145, 233-248 (1998).

79. Lee, H. et al. Massive and prolonged deep carbon emissions associated with continental rifting. Nat. Geosci. 9, 145-149 (2016). 
80. Larson, R. L. Latest pulse of Earth: evidence for a mid-Cretaceous superplume. Geology 19, 547-550 (1991).

81. Larson, R. L. Geological consequences of superplumes. Geology 19, 963-966 (1991).

82. Carter, L. B. \& Dasgupta, R. Effect of melt composition on crustal carbonate assimilation - implications for the transition from calcite consumption to skarnification and associated $\mathrm{CO}_{2}$ degassing. Geochem. Geophys. Geosyst. 17, 3893-3916 (2016).

83. Carter, L. B. \& Dasgupta, R. Hydrous basalt-limestone interaction at crustal conditions: implications for generation of ultracalcic melts and outflux of $\mathrm{CO}_{2}$ at volcanic arcs. Earth Planet. Sci. Lett. 427, 202-214 (2015).

84. Deegan, F. M. et al. Magma-carbonate interaction processes and associated $\mathrm{CO}_{2}$ release at Merapi volcano, Indonesia: insights from experimental petrology. J. Petrol. 51, 1027-1051 (2010).

85. Carter, L. B. \& Dasgupta, R. Decarbonation in the $\mathrm{Ca}-\mathrm{Mg}-\mathrm{Fe}$ carbonate system at mid-crustal pressure as a function of temperature and assimilation with arc magmas implications for long-term climate. Chem. Geol. 492, 30-48 (2018).

86. Mason, E., Edmonds, M. \& Turchyn, A. V. Remobilization of crustal carbon may dominate volcanic arc emissions. Science 357, 290-294 (2017).

87. McKenzie, N. R., Hughes, N. C., Gill, B. C. \& Myrow, P. M. Plate tectonic influences on Neoproterozoic-early Paleozoic climate and animal evolution. Geology 42, 127-130 (2014).

88. McKenzie, N. R. et al. Continental arc volcanism as the principal driver of icehousegreenhouse variability. Science 352, 444-447 (2016).

89. Johansson, L., Zahirovic, S. \& Muller, R. D. The interplay between the eruption and weathering of large igneous provinces and the deep-time carbon cycle. Geophys. Res. Lett. 45, 5380-5389 (2018).

90. Brune, S., Williams, S. E. \& Muller, R. D. Potential links between continental rifting, $\mathrm{CO}_{2}$ degassing and climate change through time. Nat. Geosci. 10, 941-946 (2017).

91. Ferry, J. M. Dehydration and decarbonation reactions as a record of fluid infiltration. Rev. Mineral. Geochem. 26, 351-391 (1991).

92. Spear, F. S. Metamorphic Phase Equilibria and Pressure-Temperature-Time Paths. (Mineralogical Society of America, 1993).

93. Ague, J. J. \& Nicolescu, S. Carbon dioxide released from subduction zones by fluidmediated reactions. Nat. Geosci. 7, 355-360 (2014).

94. Evans, M. J., Derry, L. A. \& France-Lanord, C. Degassing of metamorphic carbon dioxide from the Nepal Himalaya. Geochem. Geophys. Geosyst. 9, Q04021 (2008).

95. Lee, C.-T. A. et al. Two-step rise in atmospheric oxygen linked to the growth of continents. Nat. Geosci. 9, 417-424 (2016).

96. Evans, M. J., Derry, L. A. \& France-Lanord, C. Geothermal fluxes of alkalinity in the Narayani river system of central Nepal. Geochem. Geophys. Geosyst. 5, Q08011 (2004).

97. Jacobson, A. D., Blum, J. D. \& Walter, L. M. Reconciling the elemental and Sr isotope composition of Himalayan weathering fluxes: insights from the carbonate geochemistry of stream waters. Geochim. Cosmochim. Acta 66, 3417-3429 (2002).

98. Walker, J. C. G. \& Opdyke, B. C. Influence of variable rates of neritic carbonate deposition on atmospheric carbon dioxide and pelagic sediments. Paleoceanography 10, 415-427 (1995).

99. Zeebe, R. E. \& Westbroek, P. A simple model for the $\mathrm{CaCO}_{3}$ saturation state of the ocean: the "Strangelove," the "Neritan," and the "Cretan" Ocean. Geochem. Geophys. Geosyst. 4, 1104 (2003). 
100. Torres, M. A., West, A. J. \& Li, G. Sulphide oxidation and carbonate dissolution as a source of $\mathrm{CO}_{2}$ over geological timescales. Nature 507, 346-349 (2014).

101. Galy, V. \& Eglinton, T. Protracted storage of biospheric carbon in the GangesBrahmaputra basin. Nat. Geosci. 4, 843-847 (2011).

102. Isson, T. T. \& Planavsky, N. J. Reverse weathering as a long-term stabilizer of marine $\mathrm{pH}$ and planetary climate. Nature 560, 471-475 (2018).

103. Moon, S., Chamberlain, C. P. \& Hilley, G. E. New estimates of silicate weathering rates and their uncertainties in global rivers. Geochim. Cosmochim. Acta 134, 257-274 (2014).

104. Coogan, L. A. \& Gillis, K. M. Evidence that low-temperature oceanic hydrothermal systems play an important role in the silicate-carbonate weathering cycle and longterm climate regulation. Geochem. Geophys. Geosyst. 14, 1771-1786 (2013).

105. Alt, J. \& Teagle, D. A. H. The uptake of carbon during alteration of ocean crust. Geochim. Cosmochim. Acta 63, 1527-1535 (1999).

106. Gillis, K. M. \& Coogan, L. A. Secular variation in carbon uptake into the ocean crust. Earth Planet. Sci. Lett. 302, 385-392 (2011).

107. Staudigel, H., Hart, S. R., Schmincke, H.-U. \& Smith, B. M. Cretaceous ocean crust at DSDP Sites 417 and 418: carbon uptake from weathering versus loss by magmatic outgassing. Geochim. Cosmochim. Acta 53, 3091-3094 (1989).

108. Coogan, L. A. \& Dosso, S. E. Alteration of ocean crust provides a strong temperature dependent feedback on the geological carbon cycle and is a primary dirver of the Sr-isotopic composition of seawater. Earth Planet. Sci. Lett. 415, 38-46 (2015).

109. Schidlowski, M. A 3,800-million-year isotopic record of life from carbon in sedimentary rocks. Nature 333, 313-318 (1988).

110. Krissansen-Totton, J., Buick, R. \& Catling, D. C. A statistical analysis of the carbon isotope record from the Archean to Phanerozoic and implications for the rise of oxygen. Am. J. Sci. 315, 275-316 (2015).

111. Shields, G. A. \& Mills, B. J. W. Tectonic controls on the long-term carbon isotope mass balance. Proc. Natl Acad. Sci. 114, 4318-4323 (2017).

112. Plank, T. \& Langmuir, C. H. The chemical composition of subducting sediment and its consequences for the crust and mantle. Chem. Geol. 145, 325-394 (1998).

113. Kerrick, D. M. \& Connolly, J. A. D. Metamorphic devolatilization of subducted oceanic metabasalts: implications for seismicity, arc magmatism and volatile recycling. Earth Planet. Sci. Lett. 189, 19-29 (2001).

114. Kerrick, D. M. \& Connolly, J. A. D. Metamorphic devolatilization of subducted marine sediments and transport of volatiles into the Earth's mantle. Nature 411, 293-296 (2001).

115. Kump, L. R., Brantley, S. L. \& Arthur, M. A. Chemical weathering, atmospheric $\mathrm{CO}_{2}$, and climate. Annu. Rev. Earth Planet. Sci. 28, 611-667 (2000).

116. Winnick, M. J. \& Maher, K. Relationships between $\mathrm{CO}_{2}$, thermodynamic limits on silicate weathering, and the strength of the silicate weathering feedback. Earth Planet. Sci. Lett. 485, 111-120 (2018).

117. Pagani, M., Caldeira, K., Berner, R. A. \& Beerling, D. J. The role of terrestrial plants in limiting atmospheric $\mathrm{CO}_{2}$ decline over the past 24 million years. Nature $\mathbf{4 6 0}$, 85-88 (2009).

118. PALAEOSENS. Making sense of palaeoclimate sensitivity. Nature 491, 683-691 (2012).

119. Laidler, K. Chemical Kinetics, 3rd edn. (Harper \& Row, 1987). 
120. Maher, K. \& Chamberlain, C. P. Hydrologic regulation of chemical weathering and the geologic carbon cycle. Science 343, 1502-1504 (2014).

121. Held, I. M. \& Soden, B. J. Robust responses of the hydrological cycle to global warming. J. Clim. 19, 5686-5699 (2006).

122. Berner, R. A. GEOCARB II: a revised model of atmospheric $\mathrm{CO}_{2}$ over Phanerozoic time. Am. J. Sci. 294, 56-91 (1994).

123. West, J. Thickness of the chemical weathering zone and implications for erosional and climatic drivers of weathering and for carbon-cycle feedbacks. Geology $\mathbf{4 0}$, 811-814 (2012).

124. Raymo, M. E., Ruddiman, W. F. \& Froelich, P. N. Influence of late Cenozoic mountain building on ocean geochemical cycles. Geology 16, 649-653 (1988).

125. Raymo, M. E. \& Ruddiman, W. F. Tectonic forcing of late Cenozoic climate. Nature 359, 117-122 (1992).

126. Rudnick, R. L. \& Fountain, D. M. Nature and composition of the continental crust: a lower crustal perspective. Rev. Geophys. 33, 267-309 (1995).

127. Ibarra, D. E. et al. Differential weathering of basaltic and granitic catchments from concentration-discharge relationships. Geochim. Cosmochim. Acta 190, 265-293 (2016).

128. Dessert, C., Dupre, B., Gaillardet, J., Francois, L. M. \& Allegre, C. J. Basalt weathering laws and the impact of basalt weathering on the global carbon cycle. Chem. Geol. 202, 257-273 (2003).

129. Gislason, S. R., Arnorsson, S. \& Armannsson, H. Chemical weathering of basalt as deduced from the composition of precipitation, rivers and rocks in SW Iceland. Am. J. Sci. 296, 3-77 (1996).

130. Farner, M. J. \& Lee, C.-T. A. Effects of crustal thickness on magmatic differentiation in subduction zone volcanism: a global study. Earth Planet. Sci. Lett. 470, 96-107 (2017).

131. Tang, M., Chen, K. \& Rudnick, R. L. Archean upper crust transition from mafic to felsic marks the onset of plate tectonics. Science 351, 372-375 (2016).

132. Keller, C. B. \& Schoene, B. Statistical geochemistry reveals disruption in secular lithospheric evolution about 2.5 Gyr ago. Nature 485, 490-493 (2012).

133. Krissansen-Totton, J. \& Catling, D. C. Constraining climate sensitivity and continental versus seafloor weathering using an inverse geological carbon cycle model. Nat. Commun. 8, 15423 (2017).

134. Lee, C.-T. A. et al. Deep mantle roots and continental emergence: implications for whole-Earth elemental cycling, long-term climate, and the Cambrian explosion. Int. Geol. Rev. 60, 431-448 (2018).

135. Lee, C.-T. A., Lee, T.-C. \& Wu, C.-T. Modeling the compositional evolution of recharging, evacuating, and fractionating (REFC) magma chambers: implications for differentiation of arc magmas. Geochim. Cosmochim. Acta 143, 8-22 (2014).

136. McGovern, P. J. \& Schubert, G. Thermal evolution of the earth - effects of volatile exchange between atmosphere and interior. Earth Planet. Sci. Lett. 96, 27-37 (1989).

137. Ridgwell, A. \& Zeebe, R. E. The role of the global carbonate cycle in the regulation and evolution of the Earth system. Earth Planet. Sci. Lett. 234, 299-315 (2005).

138. Ridgwell, A. A mid-Mesozoic revolution in the regulation of ocean chemistry. Marine Geol. 217, 339-357 (2005).

139. Korenaga, J., Planavsky, N. J. \& Evans, D. A. D. Global water cycle and the coevolution of the Earth's interior and surface environment. Philos. Trans. A Math. Phys. Eng. Sci. 375, 20150393 (2016). 
140. Flament, N., Coltice, N. \& Rey, P. F. A case for late-Archaean continental emergence from thermal evolution models and hypsometry. Earth Planet. Sci. Lett. 275, 326-336 (2008).

141. Jenkyns, H. C., Forster, A., Schouten, S. \& Sinninghe Damste, J. S. High temperatures in the late Cretaceous Arctic ocean. Nature 432, 888-892 (2004).

142. Haq, B. U., Hardenbol, J. \& Vail, P. R. Chronology of fluctuating sea levels since the Triassic. Science 235, 1156-1167 (1987).

143. Vail, P. R., Mitchum, R. W. \& Thompson, S. Seismic stratigraphy and global changes of sea level, part 4: global cycles of relative changes of sea level. Am. Assoc. Pet. Geol. Memoirs 26, 82-97 (1977).

144. Aiuppa, A., Fischer, T. P., Plank, T., Robidoux, P. \& Di Napoli, R. Along-arc, interarc and arc-to-arc variations in volcanic gas $\mathrm{CO}_{2} / \mathrm{S}_{\mathrm{T}}$ ratios reveal dual source of carbon in arc volcanism. Earth Sci. Rev. 168, 24-47 (2017).

145. Cao, W., Lee, C.-T. A. \& Lackey, J. S. Episodic nature of continental arc activity since 750 Ma: a global compilation. Earth Planet. Sci. Lett. 461, 85-95 (2017).

146. Pall, J. et al. The influence of carbonate platform interactions with subduction zone volcanism on palaeo-atmospheric $\mathrm{CO}_{2}$ since the Devonian. Clim. Past 14, 857-870 (2018).

147. Jiang, H. \& Lee, C.-T. A. Coupled magmatism-erosion in continental arcs: reconstructing the history of the Cretaceous Peninsular Ranges batholith, southern California through detrital hornblende barometry in forearc sediments. Earth Planet. Sci. Lett. 472, 69-81 (2017).

148. Lee, C.-T. A., Thurner, S., Paterson, S. R. \& Cao, W. The rise and fall of continental arcs: interplays between magmatism, uplift, weathering and climate. Earth Planet. Sci. Lett. 425, 105-119 (2015).

149. Lenardic, A. et al. Continents, super-continents, mantle thermal mixing, and mantle thermal isolation: theory, numerical simulations, and laboratory experiments. Geochem. Geophys. Geosyst. 12, Q10016 (2010).

150. Kent, D. V. \& Muttoni, G. Equatorial convergence of India and early Cenozoic climate trends. Proc. Natl Acad. Sci. 105, 16065-16070 (2008).

151. Hodell, D. A. et al. Variations in the strontium isotope composition of seawater during the Paleocene and early Eocene from ODP Leg 208 (Walvis Ridge). Geochem. Geophys. Geosyst. 8, Q09001 (2007).

152. Bataille, C. P., Willis, A., Yang, X. \& Liu, X.-M. Continental crust composition: a major control of past global chemical weathering. Sci. Adv. 3, e1602183 (2017).

153. Peucker-Ehrenbrink, B., Ravizza, G. \& Hofmann, A. W. The marine 187Os/186Os record of the past 80 million years. Earth Planet. Sci. Lett. 130, 155-167 (1995).

154. Peucker-Ehrenbrink, B. \& Ravizza, G. The marine osmium isotope record. Terra Nova 12, 205-219 (2000).

155. Jagoutz, O., Macdonald, F. A. \& Royden, L. Low-latitude arc-continent collision as a driver for global cooling. Proc. Natl Acad. Sci. 113, 4935-4940 (2016).

156. Kent, D. V. et al. A case for a comet impact trigger for the Paleocene/Eocene thermal maximum and carbon isotope excursion. Earth Planet. Sci. Lett. 211, 13-26 (2003).

157. Berner, R. A., Lasaga, A. C. \& Garrels, R. M. The carbonate-silicate geochemical cycle and its effect on atmospheric carbon dioxide over the past 100 million years. Am. J. Sci. 284, 641-683 (1983).

158. Tranter, M. et al. Geochemical weathering at the bed of Haut Glacier d'Arolla, Switzerland - a new model. Hydrol. Process 16, 959-993 (2002). 
159. Torres, M. A., Moosdorf, N., Hartmann, J., Adkins, J. F. \& West, A. J. Glacial weathering, sulfide oxidation, and global carbon cycle feedbacks. Proc. Natl Acad. Sci. 114, 8716-8721 (2017).

160. Jenkyns, H. C. Cretaceous anoxic events: from continents to oceans. J. Geol. Soc. Lond. 137, 171-188 (1980).

161. Slotnick, B. S. et al. Early Paleogene variations in the calcite compensation depth: new constraints using old borehole sediments from across Ninetyeast Ridge, central Indian Ocean. Clim. Past 11, 473-493 (2015).

162. Cramer, B. S. \& Kent, D. V. Bolide summer: the Paleocene/Eocene thermal maximum as a response to an extraterrestrial trigger. Palaeogeog. Palaeoclimatol. Palaeoecol. 224, 144-166 (2005).

163. Kurtz, A. C., Kump, L. R., Arthur, M. A., Zachos, J. C. \& Paytan, A. Early Cenozoic decoupling of the global carbon and sulfur cycles. Paleoceanography 18, 1090 (2003).

164. Storey, M., Duncan, R. A. \& Swisher, C. C. Paleocene-Eocene thermal maximum and the opening of the Northeast Atlantic. Science 316, 587-589 (2007).

165. Selby, D., Mutterlose, J. \& Condon, D. J. U-Pb and Re-Os geochronology of the Aptian/Albian and Cenomanian/Turonian stage boundaries: implications for timescale calibration, osmium isotope seawater composition and Re-Os systematics in organic-rich sediments. Geology 265, 394-409 (2009).

166. Leckie, R. M., Bralower, T. J. \& Cashman, R. Oceanic anoxic events and plankton evolution: biotic response to tectonic forcing during the mid-Cretaceous. Paleoceanography 17, 13-1-13-29 (2002).

167. Cox, G. M. et al. Continental flood basalt weathering as a trigger for Neoproterozoic Snowball Earth. Earth Planet. Sci. Lett. 446, 89-99 (2016).

168. Godderis, Y. \& Francois, L. M. The Cenozoic evolution of the strontium and carbon cycles: relative importance of continental erosion and mantle exchanges. Chem. Geol. 126, 169-190 (1995).

169. White, A. F., Schulz, M. S., Lowenstern, J. B., Vivit, D. V. \& Bullen, T. D. The ubiquitous nature of accessory calcite in granitoid rocks: implications for weathering, solute evolution, and petrogenesis. Geochim. Cosmochim. Acta 69, 1455-1471 (2005).

170. Husson, J. M. \& Peters, S. E. Atmospheric oxygenation driven by unsteady growth of the continental sedimentary reservoir. Earth Planet. Sci. Lett. 460, 68-75 (2017). 